University of Montana

ScholarWorks at University of Montana

$1-1996$

\title{
Scaling of Muscle Composition, Wing Morphology, and Intermittent Flight Behavior in Woodpeckers
}

Bret W. Tobalske

University of Montana - Missoula, bret.tobalske@mso.umt.edu

Follow this and additional works at: https://scholarworks.umt.edu/biosci_pubs

Part of the Biology Commons

Let us know how access to this document benefits you.

\section{Recommended Citation}

Tobalske, Bret W., "Scaling of Muscle Composition, Wing Morphology, and Intermittent Flight Behavior in Woodpeckers" (1996). Biological Sciences Faculty Publications. 212.

https://scholarworks.umt.edu/biosci_pubs/212

This Article is brought to you for free and open access by the Biological Sciences at ScholarWorks at University of Montana. It has been accepted for inclusion in Biological Sciences Faculty Publications by an authorized administrator of ScholarWorks at University of Montana. For more information, please contact scholarworks@mso.umt.edu. 


\title{
SCALING OF MUSCLE COMPOSITION, WING MORPHOLOGY, AND INTERMITTENT FLIGHT BEHAVIOR IN WOODPECKERS
}

\author{
BRET W. TOBALSKE \\ Division of Biological Sciences, University of Montana, Missoula, Montana 59812, USA
}

\begin{abstract}
Existing theory and empirical evidence suggest that body size should have a profound influence upon the composition of flight muscles and the performance of intermittent flight in birds. I examine the relationships between functional morphology and intermittent flight behavior within a closely-related group of birds using six species of woodpeckers (Picidae): Downy Woodpecker (Picoides pubescens, $27.2 \mathrm{~g}$ ), Red-naped Sapsucker (Sphyrapicus nuchalis, $47.4 \mathrm{~g}$ ), Hairy Woodpecker (P. villosus, $70.5 \mathrm{~g})$, Lewis' Woodpecker (Melanerpes lewis, $106.6 \mathrm{~g}$ ), Northern Flicker (Colaptes auratus, $148.1 \mathrm{~g}$ ), and Pileated Woodpecker (Dryocopus pileatus, $262.5 \mathrm{~g}$ ). In woodpeckers with a body mass less than $100 \mathrm{~g}$, the pectoralis muscle was composed mostly of red $(R)$ fibers, with intermediate $(I)$ fibers either absent or restricted to lateral regions. $R$ and $I$ fibers were found in all regions of the pectoralis in the larger species. Positive scaling of the percent and cross-sectional diameter of $I$ fibers may explain why species larger than $100 \mathrm{~g}$ flap-bounded when theory predicts they should not have sufficient power. Differences were evident in staining characteristics of $I$ fibers among (but not within) species. Phylogenetic effects were apparent because hypothesized sister taxa shared similarities in muscle composition. Internal and external wing dimensions scaled according to the predictions of geometric similarity, but the Red-naped Sapsucker and Lewis' Woodpecker possessed slightly higher wing-shape indices (narrower, more-pointed wings) than the other species, which may reflect migratory and flycatching behavior as well as phylogeny. All of the species exhibited flap-bounding. The number of flaps in a flapping phase, wingbeat frequency, flapping-phase duration, and bounding-phase duration all scaled negatively with body mass, whereas the percent time spent flapping and flight speed scaled slightly positively. Lewis' Woodpecker was unusual in its intermittent flight behavior by spending more time flapping, using lower wingbeat frequencies and flying slower than would be expected for its body mass. It was the only species to pursue flying insects using highly maneuvered flights including extended glides, although the Red-naped Sapsucker was observed to flycatch without gliding. Slow flight speed, rather than wing design, was related to gliding in the Lewis' Woodpecker. I fibers in the pectoralis of the Lewis' Woodpecker were unique in showing intense glycolytic potential, perhaps reflecting the species' foraging style. Received 2 May 1995, accepted 21 August 1995.
\end{abstract}

INTERMITTENT FLIGHT consists of regular alternation between flapping phases and nonflapping phases during which a bird's wings are either held fully flexed (flap-bounding) or extended (flap-gliding). Intermittent flight is exhibited by many bird species, and the subject has fostered extensive theoretical treatment. Mathematical models of intermittent flight address power output because, per unit time, flapping flight is the most energetically expensive form of vertebrate locomotion (Goldspink 1981, Hudson and Bernstein 1983, Schmidt-Nielsen 1984). In general, the models predict that flapbounding flight can offer an energetic savings relative to continuous flapping if a bird is flying at or faster than maximum-range velocity $\left(V_{\mathrm{mr}}\right.$; Lighthill 1977, Rayner 1977, 1985a, Alexander 1982, Ward-Smith 1984a), whereas flap-gliding flight should be less costly than continuous flapping at or slower than minimum-power velocity ( $V_{\mathrm{mp}}$; Ward-Smith $1984 \mathrm{~b}$, Rayner 1985a). DeJong's (1983) model of intermittent flight includes both bounds and brief glides ("turnouts") during nonflapping phases and predicts that birds using such behavior could gain energetic savings relative to continuous flapping during flight across a wide range of speeds.

Smaller bird species, with the exception of hummingbirds (Trochilidae), tend to flap-bound (e.g. small passerines, Passeriformes), and medium- to large-sized bird species (e.g. falcons, Falconidae) tend to flap-glide (Lighthill 1977, Rayner 1977, 1985a, Alexander 1982, DeJong 1983, Ward-Smith 1984a, b). The available evidence, though not extensive, suggests that these flight styles are fixed for particularly small species that only flap-bound (e.g. Zebra Finch [Taenopygia guttatta], average body mass $15 \mathrm{~g}$; 
Scholey 1983, Rayner 1985a) and for relatively large species that only flap-glide (e.g. Rock Dove [Columba livia], $350 \mathrm{~g}$; Pennycuick 1968a, Tobalske and Dial 1996). Species of intermediate body mass, specifically the Budgerigar (Melopsittacus undulatus, $35 \mathrm{~g}$ ), European Starling (Sturnus vulgaris, $75 \mathrm{~g}$ ), and Black-billed Magpie (Pica pica, $175 \mathrm{~g}$ ), can facultatively change from flap-gliding at slow speeds to flap-bounding at fast speeds (Tobalske and Dial 1994, 1996, Tobalske 1995). At any given speed, however, the percentage of glides, as opposed to bounds, among all nonflapping phases, increases with increasing body mass.

Why do these general correlations with body mass exist? One explanation is based upon the composition of the primary flight muscle, the pectoralis, which comprises up to $20 \%$ of the body mass of a bird (George and Berger 1966). Many small species have only red $(R)$ fast-twitch fibers in their pectoralis muscle (Rosser and George 1986a). According to the "fixed-gear" hypothesis (Goldspink 1977, 1981, Rayner 1977, 1985a), small body size imposes a limit on the heterogeneity of fiber types in the pectoralis. This in turn limits the range of efficient contractile velocities and power output in the muscle, making it inefficient for small birds to vary substantially their wingbeat frequency and amplitude. Gliding, with isometric contractions of the flight muscles (Meyers 1993, Tobalske and Dial 1994, Tobalske 1995), would be uneconomical for the same reason (Goldspink 1977, 1981, Rayner 1977, 1985a). Thus, the fixed-gear hypothesis states that the only way for small birds to efficiently reduce power output below the maximum sustainable power (e.g. to fly at $V_{\text {mp }}$ ), is to intermittently bound (Rayner 1977, 1985a).

In contrast, larger birds may recruit different muscle fiber types (i.e. "shift gears") to vary power output in flight (Goldspink 1977, 1981, Rayner 1977, 1985a). The Rock Dove possesses two distinct fast-twitch fiber types in its pectoralis ( $R$ and white $[W])$. The $W$ fibers, larger in diameter, are believed to be selectively recruited during flight modes that require high power output, such as takeoff and vertical ascent, and the bird may switch to exclusive use of the smaller-diameter $R$ fibers for contractions during level flight (Dial et al. 1988, Dial and Biewener 1993). Other species, such as the Turkey Vulture (Cathartes atratus), have two different fast-twitch fiber types ( $R$ and intermediate
[I]) and also a distinct region of predominantly slow-twitch fibers (Rosser and George 1986b). The fast-twitch fibers presumably are used during flapping, and the slow-twitch fibers are likely to be selected for their economy during isometric contractions while gliding (Rosser and George 1986b).

Larger birds in fact may be unable to engage in intermittent bounds, according to the "adverse-scaling" hypothesis, because of the adverse scaling of available power from the flight muscles, or because of the adverse scaling of flight performance including acceleration and climbing ability (Lighthill 1977, Rayner 1977, 1985a, DeJong 1983, Tobalske and Dial 1996). Both theoretical predictions and empirical evidence show that the mass-specific power required for flight at a given airspeed scales approximately proportional to body mass raised to the 0.16 power $\left(M^{0.16}\right)$. Meanwhile, the massspecific power available from the flight muscles is predicted to scale somewhere between $\mathbf{M}^{0.00}$ and $\mathrm{M}^{-0.33}$ (Pennycuick 1968b, Rayner 1977, Pennycuick and Rezende 1984, Ellington 1991). The adverse scaling of available power relative to power required sets a limit above which flapbounding is no longer feasible because a bird larger than the limit would be unable to generate sufficient lift and thrust during a fraction of the total flight time and still maintain a level average flight altitude (Lighthill 1977, Rayner 1977, 1985a, DeJong 1983, Tobalske and Dial 1996). Empirical observations show that the mass-specific available power from the flight muscles actually scales positively with body mass and proportional to $\mathrm{M}^{0.13}$, which at first appears to undermine the argument for adverse scaling (Marden 1987, 1994, Ellington 1991). However, Marden (1994) showed that flight performance (defined as lift per unit of power output) scales negatively with increasing body mass and approximately proportional to $\mathrm{M}^{-0.44}$, thereby offering an alternative explanation for a size limit to flap-bounding flight. DeJong (1983) used empirical observations of acceleration in birds to propose that the size limit is approximately 100 $\mathrm{g}$, which agrees with the $100-\mathrm{g}$ limit predicted in the model of Rayner (1977, 1985a).

Woodpeckers (Picidae) often are cited as examples of typical flap-bounding birds, and the Green Woodpecker (Picus viridus; mean body mass $176 \mathrm{~g}$; Dunning 1993) is one of the largest species reported to flap-bound (Alexander 1982, DeJong 1983, Ward-Smith 1984a, Rayner 1985a). 
Different species of woodpeckers range in body mass from less than $30 \mathrm{~g}$ to over $300 \mathrm{~g}$ (Dunning 1993), which is well above the predicted size limit for flap-bounding flight (Rayner 1977, 1985a, DeJong 1983). The flight style of most of the $200+$ species of woodpeckers is described as "heavy" or "undulating" (Skutch 1985), probably in relation to their flap-bounding flight. However, one unusual species, the Lewis' Woodpecker (Melanerpes lewis), is reported to glide extensively while foraging for flying insects (Bent 1939, Bock 1970). This species' flight path during flapping is described as straight and "crowlike," as is the flight path of some of the larger species, including the Pileated Woodpecker (Dryocopus pileatus; Short 1982, Skutch 1985).

Woodpeckers thus represent a useful taxonomic group for studying the relationships between body mass and intermittent flight. I present the results of a comparative analysis of new morphological, physiological, and behavioral data related to intermittent flight in the following six woodpecker species: Downy Woodpecker (Picoides pubescens), Hairy Woodpecker (P. villosus), Red-naped Sapsucker (Sphyrapicus nuchalis), Lewis' Woodpecker, Northern Flicker (Colaptes auratus), and Pileated Woodpecker. Using these data, I evaluate predictions of the fixedgear hypothesis that the heterogeneity of fiber types in the pectoralis should increase with increasing body mass and that gliding behavior should be associated with the presence of slower fibers in the muscle (Goldspink 1977, Rayner 1977, 1985a). I also examine the predictions, from the adverse-scaling hypothesis, that there should be a size limit for the ability to bound, and the percentage of flight time spent flapping during flap-bounding flight should scale positively with body mass (Lighthill 1977, DeJong 1983, Rayner 1977, 1985a, Tobalske and Dial 1996). Lastly, my field observations permit a test of the prediction from wind-tunnel studies that birds should facultatively switch from flap-gliding at slow speeds to flap-bounding at fast speeds to efficiently reduce mechanical and metabolic power output during flight at all speeds (Tobalske and Dial 1994, 1996, Tobalske 1995).

\section{METHODS}

Histology.-Pectoralis muscles from six species of North American woodpeckers (all adults) were studied using histological staining techniques: Downy
Woodpecker $(n=2)$, Red-naped Sapsucker $(n=3)$, Hairy Woodpecker $(n=2)$, Lewis' Woodpecker $(n=$ 2), Northern Flicker $(n=2)$, and Pileated Woodpecker $(n=1)$. Pectoralis muscles from one chicken (Gallus gallus), one Rock Dove, and one European Starling were used as controls based on previous research on these species (Rosser and George 1986a). I collected most of the woodpeckers from the field during $\mathrm{Au}-$ gust and September 1992. Other birds were donated to my study as fresh specimens following accidental collisions with automobiles. The chicken was a fresh (not frozen) store-bought specimen, and the Rock Dove and European Starling were wild-caught birds that were used in different studies at the University of Montana. Both the left and right pectoralis muscles were dissected from each specimen and quickly frozen by whole immersion in liquid nitrogen $\left(-160^{\circ} \mathrm{C}\right)$. The frozen muscles were wrapped in parafilm, placed in sealed plastic bags, and stored at $-80^{\circ} \mathrm{C}$ until they were used for sectioning and staining.

Using a cryostat microtome (International Equipment Co. Model CTD) set at $-20^{\circ} \mathrm{C}$, serial transverse sections approximately $14 \mu \mathrm{m}$ thick were cut from the midbelly of each pectoralis muscle (Fig. 1) and then mounted on glass microscope slides. For the smaller species, the entire transverse section of the muscle was prepared on a single microscope slide. For the larger species, separate slides of the medial and lateral portions of the muscle were prepared so that the transverse section of the entire muscle was represented. Sections from other parts of each pectoralis were prepared, but only the midbelly transverse sections from either a left or right side were used for quantitative analysis.

Multiple sections of each muscle were stained for myofibrillar adenosine triphosphatase (mATPase) activity (Padykula and Herman 1955, Guth and Samaha 1970) following the methods of Hermanson and Foehring (1988) and Rosser and George (1986a). These sections were preincubated in a $0.2 \mathrm{M}$ barbital acetate buffer ( $\mathrm{pH} \mathrm{4.2)}$ for $5 \mathrm{~min}$ at $25^{\circ} \mathrm{C}$. After preincubation, the sections were incubated for $30 \mathrm{~min}$ in sodium barbital buffer solution (1.4 mM ATP, $18 \mathrm{mM} \mathrm{CaCl}_{2}$, $\mathrm{pH} 9.4)$ at $37^{\circ} \mathrm{C}$. Because of tissue slippage, alkaline preincubations (Rosser and George 1986a) were not performed on all specimens. Corresponding serial sections were stained in a succinate dehydrogenase (SDH) solution at $37^{\circ} \mathrm{C}$ for $30 \mathrm{~min}$ to demonstrate oxidative capacity (Rosser and George 1986a, Loeb and Gans 1986), or in an alpha-glycerophosphate dehydrogenase (GPD) solution at $37^{\circ} \mathrm{C}$ for $60 \mathrm{~min}(9.3$ mM GPD, $1.2 \mathrm{mM}$ Nitro Blue Tetrazolium, and 2.3 $\mathrm{mM}$ menadione) to demonstrate glycolytic capacity (Wattenberg and Leong 1960, Hermanson and Foehring 1988).

Following staining, serial tissue sections were photographed for analysis of fiber types including classification, counting, and measuring cross-sectional diameter. An Olympus PM-10ADS automatic photo- 


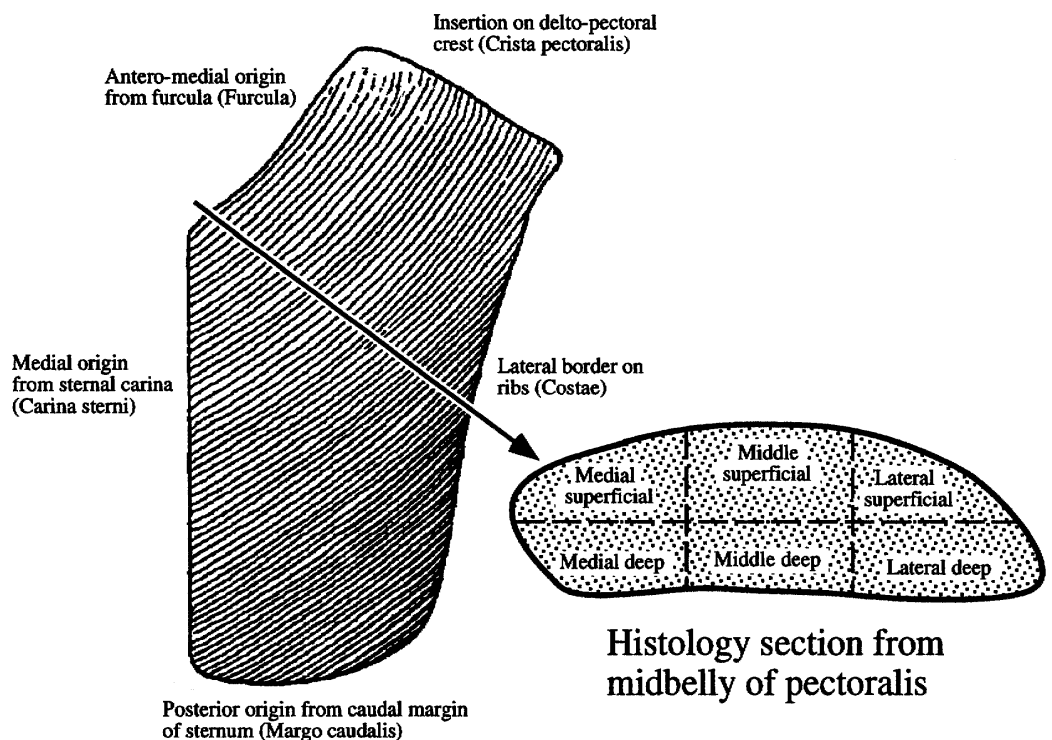

Fig. 1. On left, ventral view of whole pectoralis muscle from Pileated Woodpecker (adapted from Burt 1930) showing midbelly region of muscle from which transverse serial sections were removed for histological analysis (arrow). On right, transverse view of same muscle illustrating six different regions sampled within each serial section.

micrographic system at $100 \times$ and $400 \times$ was used for photographing the sections. Color slides (35-mm, Kodak Ektachrome 100 or Kodachrome 64) were prepared for the classification of fiber types and measurement of fiber diameters. Black-and-white prints (from 35-mm Kodak TMAX black-and-white negatives) were prepared for inclusion in this paper. Along with the muscle preparations, I photographed a 20$\mu \mathrm{m}$ microruler at both $100 \times$ and $400 \times$.

Using photographs of the mATPase preparations, individual muscle fibers were classified as either fasttwitch (light-staining after acid preincubation) or slowtwitch (dark-staining after acid preincubation; Rosser and George 1986a, Hermanson and Foehring 1988) in comparison to the fibers in the deep lateral region of the chicken pectoralis, which contained known fibers of both types (Rosser and George 1986a). The fasttwitch fibers in the woodpecker pectoralis muscles were classified further as being white $(W)$, intermediate $(I)$, or red $(R)$ using fiber diameters, SDH staining, and GPD staining. Based upon SDH staining, the Rock Dove pectoralis control contained $W$ fibers (largediameter, light-staining $\mathrm{SDH}$ ) and $R$ fibers (small-diameter, dark-staining SDH), whereas the European Starling pectoralis contained $I$ fibers (intermediatediameter, intermediate-staining $\mathrm{SDH}$ ) and $R$ fibers similar to the $R$ fibers in the Rock Dove pectoralis (George and Berger 1966, Rosser and George 1986a).

After classifying muscle fibers, I counted the number of fibers of each type using $100 \times$ photographic slides of muscle tissue taken from each of six regions across the midbelly transverse section of each wood- pecker pectoralis muscle (medial superficial, medial deep, middle superficial, middle deep, lateral superficial, and lateral deep; Fig. 1). I counted the total number of cells of each fiber type within one or more randomly-chosen fascicle boundaries in the photograph (between 400 and 2,500 cells per photograph). These totals were used to calculate the percentage of each fiber type within each region of each woodpecker pectoralis. The same photographic slides were projected onto a digitizing pad (Summagraphics BitPad Plus) on which I used custom digitizing (Bit Pad Digitize 1.3) and analysis (Cine Motion 2.0) software (Stephen Gatesy) with a MacIntosh Quadra 950 computer to measure the minimum cross-sectional diameter of 25 randomly-chosen fibers of each fiber type observed within each of the six regions from each bird's pectoralis. The bars of a $20-\mu \mathrm{m}$ microruler also were digitized from photographs and these measurements were used as a scale to convert pixels into $\mu \mathrm{m}$ using Excel 3.0 software (Microsoft Corp. 1991). The average percentage of each fiber type and average diameter for each fiber type was computed as the grand mean of six averages (one average from each region).

Morphometrics. -Fifteen gross-morphological variables were measured from adult specimens of each species. Sample sizes ranged from 2 to 30 depending upon the species and the variable measured. All of the gross morphological variables were measured in each of the birds that were used for histological study. In addition, some measurements were obtained from previously-frozen and fluid-preserved birds, as well 
as cleaned and dried skeletal preparations and dried, spread wings.

Mass was measured to the nearest $0.01 \mathrm{~g}$ (with a Mettler PE360 digital balance) and length was measured to the nearest millimeter with a metric ruler or to the nearest $0.01 \mathrm{~mm}$ with digital calipers (Mitutoyo Digimatic). Pectoralis mass was measured as the combined mass of the left and right pectoralis muscles dissected whole from the bird and blotted dry. Body mass was measured directly in some specimens; otherwise, body mass data were recorded from the museum tags associated with the cleaned skeletons or spread wings. External wing measurements including wingspan (between tips of the 8th primaries of each wing, wing area, and wing length from proximal tip of the olecranon process of the ulna to the tip of the 8th primary) were measured with the wing(s) spread as in mid-downstroke of flapping flight (i.e. the emargination on distal third of each of the primaries was completely separated from adjacent feathers). The lengths of the 8th primary and 1st secondary were measured from the point where the feather emerged from the skin to the distal tip of the feather.

Wing area was estimated for one wing. Wing tracings on millimeter-rule graph paper were video taped (S-VHS format, Panasonic Model AG-455) and transferred to a MacIntosh Quadra 950 computer using a Panasonic AG-1960 S-VHS player and ScreenPlay software. The wing outline, including all primary and secondary feathers but no tertial feathers, was traced using Image software (N.I.H.), and wing area in centimeters squared $\left(\mathrm{cm}^{2}\right)$ was converted from pixels within the wing outline using a known scale of either 15 or $24 \mathrm{~cm}$. In cases where a feather was missing, broken, or reemerging following molt, a straight line was drawn between the tips of the adjacent two feathers using a ruler, and I sketched the outline of the missing feather by substituting the missing portion with a tracing of the corresponding portion of the adjacent proximal feather arranged so that the tip was centered on the straight line. Wings that were missing the 10th primary or two adjacent feathers were not evaluated.

An aspect-ratio index was calculated as average wing span divided by average wing chord. This measurement differed slightly from aspect ratio in Tobalske (1994), and it also differed from the conventional measurement of aspect ratio because aspect ratio is usually calculated as the square of wingspan, divided by the surface area of both wings and the portion of body between the wings (Pennycuick 1989, Norberg 1990). I calculated average wing chord by dividing the square of a single wing length by the average single wing area; thus, the area of the body between the wings was not included. As another measure of wing shape, I computed a wing-shape index (Norberg and Rayner 1987 ) by dividing the average length of the 8 th primary by the average length of the 1st secondary.

To study internal wing morphometrics, the length of eight bones were measured from either the left or right side of a specimen. Following the nomenclature and descriptions in Baumel et al. (1979), these measurements included the length of the sternum (spina externa to margo caudalis), furcula (apophysis furculae to extremis omalis claviculae, process acrocoracoideus), coracoideus (process acrocoracoideus to process lateralis), scapula (acromion to extremitas caudalis scapulae), humerus (caput humeri to condylus dorsalis), ulna (olecranon to condyla dorsalis), radius (cotyla hurneralis to facies articularis radiocarpalis), and manus (trochlea carpalis [facies articularis radiocarpalis] to facies articularis digiti minoris).

Field observations.-Adult woodpecker flights used for quantitative analysis were observed between May and September 1992-1994 in Missoula or Flathead counties, Montana, at an average elevation of 1,200 $\mathrm{m}$ above sea level. All kinematic data were recorded and analyzed using high-speed (64 frames/s), 16-mm film (Bolex camera) or Hi-8 video tape ( 60 fields/s, NTSC standard; Sony Model 910). The 16-mm film was viewed with a frame counter using a Mark IV motion-analyzer projector. The Hi-8 master videos were transferred to S-VHS with a $60 \mathrm{~Hz}$ time code added during transfer (Horita II model TG 50) and then viewed using a Panasonic AG1960 video player with jog-shuttle advance capability.

To compare flight variables among species, only sections of nonmaneuvering flights with approximately no change in mean altitude were included in the sample (Fig. 2A). Periods of intermittent flight included the first nonflapping period after takeoff to the first braking glide during landing (Fig. 2A). Flights were divided into separate "cycles" consisting of a flapping phase followed by a nonflapping phase. Wingbeat frequency (during flapping phase only), the number of flaps, the duration of the flapping phase, and the duration of the nonflapping phase were measured from each cycle. The percentage of cycle time spent flapping also was calculated. Wing flapping commenced as the tips of the wings were first elevated or depressed from the lateral-perspective midline of the body following a nonflapping phase, and ended as the wingtips reached the lateral-perspective midline of the body as a nonflapping phase began. Nonflapping phases were identified as periods longer than $50 \mathrm{~ms}$ in duration (three frames of film or fields of video) with no movement in the wingtips relative to the body. These phases were classified either as a glide (wings outstretched) or a bound (wings highly flexed almost to posture exhibited during perching).

Wing kinematics during field flights were digitized by projecting each frame of film (using MARK IV motion-analyzer projector) or field of video (using Sharp Professional Series XG-2000U Liquid Crystal Video Projector) onto a Summagraphics Bit Pad Plus digitizing pad (custom software, Bit Pad Digitize 1.3 and Cine Motion 2.0, Stephen Gatesy). Using guidelines in Scholey (1983), I limited the sample to: (1) flights when the bird was flying directly towards or away from the camera (angle between flight path and 

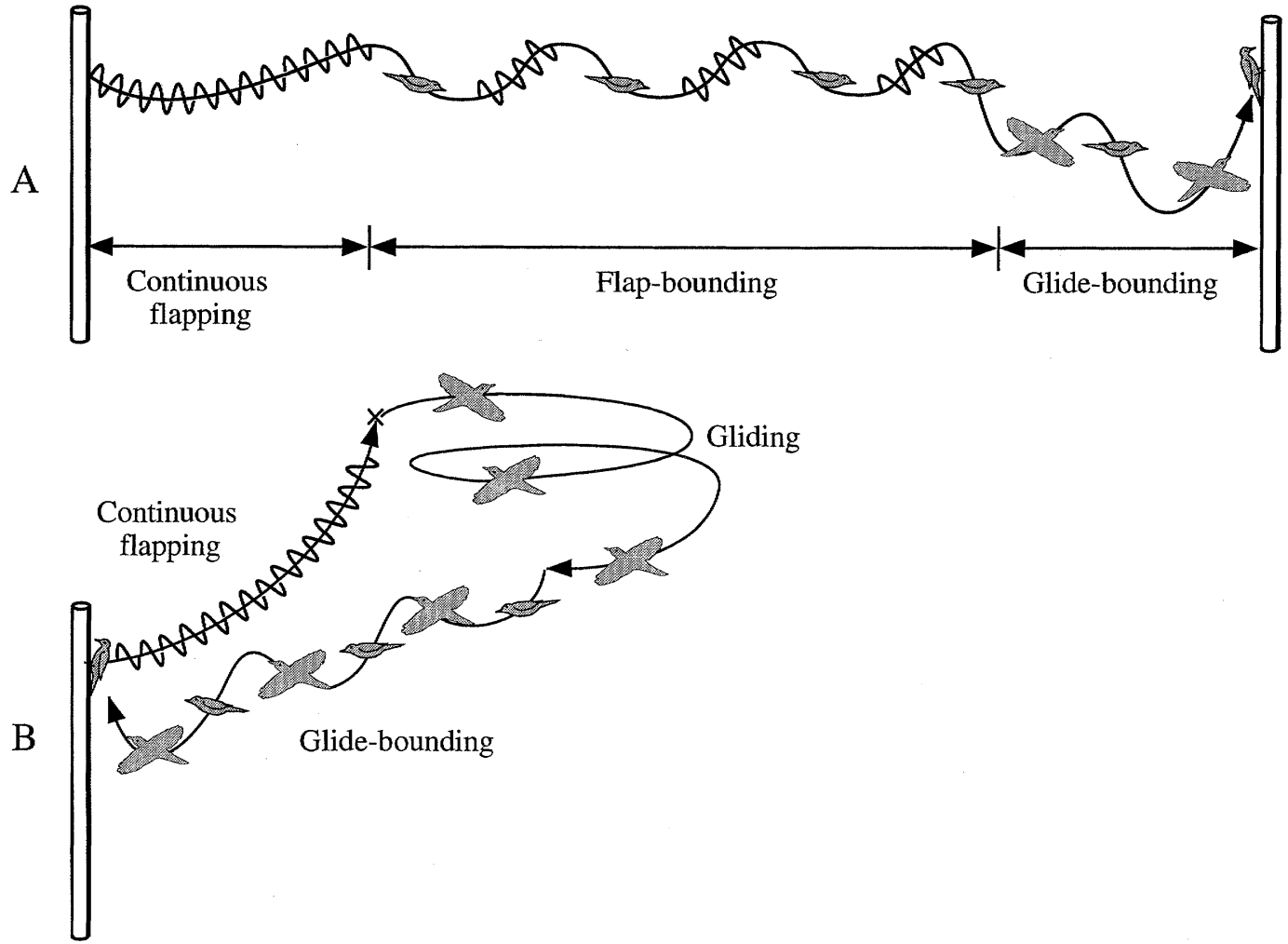

Fig. 2. (A) Flap-bounding phase of flight with mean flight path approximately level, excluding periods of continuous flapping after takeoff and periods of glide-bounding prior to landing. (B) Pursuit of flying insects during foraging flights in the Lewis' Woodpecker, which included maneuvering and extended gliding periods. " $X$ " represents insect capture. Partially modeled after Bock (1979) and Burnie (1988).

line of sight of camera $0^{\circ} \pm 10^{\circ}$ ), providing an anterior or posterior view of the bird; or (2) flights when the flight path was perpendicular to the camera (angle between flight path and line of sight of camera $90^{\circ}$ $\pm 10^{\circ}$ ), providing either a lateral or ventral view of the bird. Wingspan (distance between distal tips of 8th primaries, only available from anterior or posterior view) and wingtip elevation (distance between midline of body and straight line drawn between tips of 8 th primaries) were calculated from the digitized points. Given that the wingspan at mid-downstroke is relatively consistent for a given bird during flapping flight (Scholey 1983, Rayner 1985a, Tobalske and Dial 1996), pixel numbers representing a single wingbeat were converted to centimeters so that: (1) within each wingbeat, the wingspan at mid-downstroke was equal to the average wingspan measured on specimens used for morphometric study; and (2) the greatest absolute value for wingtip elevation during the wingbeat was equal to one-half of this average wingspan. Wingspan and wingtip elevation during nonflapping phases were scaled from pixels to centimeters using the scale of the wingbeat immediately preceding the nonflapping phase.
Flight speeds were estimated from flight times and distances covered. I recorded flight time (to nearest $0.01 \mathrm{~s}$ ) using a digital watch (Casio $\mathrm{J} 31-\mathrm{W}$ ) as a bird in flight passed between landmarks at least $20 \mathrm{~m}$ apart. The distance between the landmarks was measured (to nearest $0.5 \mathrm{~m}$ ) using a tape measure and pacing on foot. Wind speed during the flight at $3 \mathrm{~m}$ above ground level was measured with a Davis hand-held wind-speed indicator (accurate to $\pm 3 \%$ ). Flight direction and wind direction were measured with a handheld Silva compass. Ground speed was computed in meters per second and corrected for wind speed and direction relative to the bird's flight path using a NAV-COMP1 flight computer to obtain a measurement of airspeed during flight.

Statistical analysis. - Individual birds were used as sample units for histological and morphometric variables, and geographic locations (generally active nest sites including male and female bird) were used as sample units for data collected in the field. To provide an indication of the variability within birds or geographic locations for the field variables, the range of values are reported from the total number of observations from all geographic locations for a species. 
To examine scaling relationships between body mass and the histological, morphometric, and intermittent flight variables, all variables were log transformed and analyzed using reduced-major-axis (RMA) regressions (Rayner 1985b, Norberg and Rayner 1987). This regression model is appropriate for data sets in which there is statistical variation and measurement error in both the dependent and independent variables (Sokal and Rohlf 1981, Rayner 1985b). Pearson product-moment correlations (Sokal and Rohlf 1981) were calculated for use as an index of the linear association between body mass and the various dependent variables using SPSS 4.0 software (Norusis 1990). To obtain an RMA regression formula, the appropriate least-squares regression was computed using Cricket Graph III 1.5 software (Computer Associates International, Inc. 1992), the resulting coefficient for the least-squares slope was divided by the correlation coefficient $(r)$, and the new RMA regression line was computed using Excel 3.0 software (Microsoft Corp. 1991) as a line with this new slope intercepting the bivariate mean. Because the Lewis' Woodpecker was unusual in its flight behavior compared to the other woodpecker species, I computed separate correlation coefficients and RMA regressions with this species first included in and then excluded from the sample.

The independent-contrasts method (Felsenstein 1985, Garland et al. 1992) was used to correct statistically for the nonindependence of species using PDTree software (Ted Garland). Regression slopes and correlation coefficients using species data or independent contrast data were virtually identical (Tobalske 1994); thus, for ease of discussion and graph interpretation only standard RMA regressions are presented. Probability values for tests of statistical significance were obtained using SPSS software (Norusis 1990). These values apply only to the species data because the independent-contrast method reduced degrees of freedom and, thus, $P$-values (Felsenstein 1985, Garland et al. 1992).

\section{RESULTS}

Histology. - Acid preincubations of woodpecker muscle tissue contained only light-staining, acid-labile fibers (Fig. 3A) that indicated fast-twitch contractile properties (Rosser and George 1986a, Hermanson and Foehring 1988). In contrast, the chicken pectoralis (deep red strip) controls (Fig. 3B) contained large-diameter, acid-labile (fast-twitch) fibers and smallerdiameter, acid-stable (slow-twitch or slow-tonic) fibers (Rosser and George 1986a, b). An additional control within the woodpecker muscles was provided by the walls of the blood vessels (Rosser and George 1986a), which consistently stained dark as acid-stable, slow-tonic fibers (Fig. 3A).
Fast-twitch fibers in the woodpecker pectoralis muscles included $R$ and $I$ fibers using Rock Dove (Fig. 3C, D) and European Starling (Fig. $3 E, F)$ controls for comparison. The fiber diameters and histological staining of the Rock Dove and European Starling controls generally were consistent with previous investigations of the pectoralis muscles of these species (George and Berger 1966, Rosser and George 1986a), but the GPD staining of European Starling pectoralis muscle has not been reported previously. The $R$ fibers in the Rock Dove averaged $26.5 \mu \mathrm{m}$ in diameter ( $3.5 \mu \mathrm{m}$ less than average reported in George and Berger 1966), stained dark for SDH and moderate for GPD. Similar staining was observed in the $R$ fibers of the European Starling pectoralis, but the average fiber diameter was $19.8 \mu \mathrm{m}$. $W$ fibers in the Rock Dove pectoralis averaged $53.0 \mu \mathrm{m}$ in diameter $(17 \mu \mathrm{m}$ less than in George and Berger 1966) and stained very lightly for SDH and intensively for GPD. The mean diameter of $I$ fibers in the European Starling was $31.5 \mu \mathrm{m}$. These $I$ fibers stained intermediate (between $R$ and $W$ fibers in Rock Dove) for SDH activity, and intensively for GPD.

Classification of muscle fibers in the woodpecker pectoralis muscles was occasionally difficult because of intramuscular variation in the cross-sectional diameters of cells (Fig. 4A, B) and variation in staining intensity (Fig. 4C, D). These patterns of size and staining variation within a single fiber type did not appear to be related to a particular region of the midbelly of the muscle (Fig. 1). The variation in fiber diameter among the midbelly regions was evident in all of the species, but the variation in staining intensity was mostly observed among the $R$ fibers of the pectoralis muscles of Downy and Hairy woodpeckers (e.g. Fig. 4C, D). The Red-naped Sapsucker pectoralis exhibited the most uniform staining for SDH and GPD among $R$ fibers (Fig. 4E), whereas the cell types with the greatest contrast were the $I$ and $R$ fibers stained for SDH or GPD in the Pileated Woodpecker pectoralis (Fig. 4F).

$R$ fibers were present in all regions of each of the woodpeckers' pectoralis muscles (Table 1; Fig. 1). I fibers were not present in Red-naped Sapsucker muscle (Table 1; Figs. 4E and 5C, D), and were present only in the lateral superficial and lateral deep regions of the pectoralis of downy and Hairy woodpeckers (Table 1; Fig. $5 \mathrm{~A}, \mathrm{~B}, \mathrm{E}, \mathrm{F})$. I fibers were found in each of the six regions of the Lewis' Woodpecker, Northern 

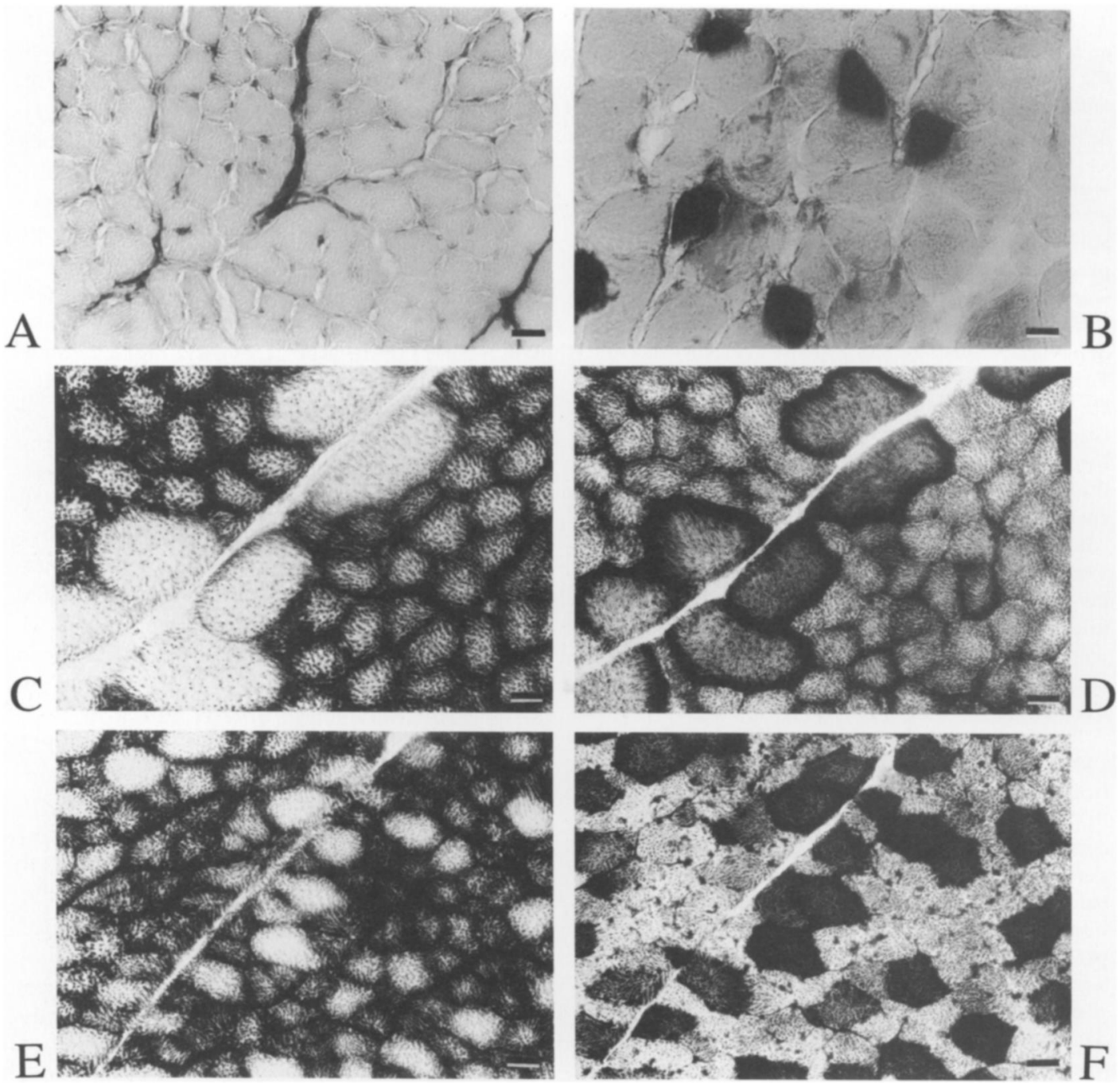

Fig. 3. (A) Downy Woodpecker pectoralis stained for mATPase activity following acid $(4.2 \mathrm{pH})$ preincubation showing fast-twitch fibers, the only fiber type found in woodpecker pectoralis muscles (stained light; acid-labile). Dark-staining walls of blood vessels, evident in section, provided within-muscle controls for slow-tonic muscle fibers. (B) Deep lateral region of chicken pectoralis stained for mATPase activity following acid $(4.2 \mathrm{pH})$ preincubation. Slow-twitch fibers stained dark (acid-stable); fast-twitch fibers stained light (acidlabile). (C) Rock Dove pectoralis muscle stained for SDH. W fibers were large in diameter and stained light; $R$ fibers were small in diameter and stained dark. (D) Serial section corresponding to panel $C$, but stained for GPD. $W$ fibers stained dark; $R$ fibers stained moderate. (E) European Starling muscle stained for SDH. $R$ fibers stained dark; $I$ fibers stained lighter than $R$ fibers, but darker than $W$ fibers in Rock Dove and were intermediate in diameter. (F) Serial section of European Starling muscle corresponding to panel E, but stained for GPD. Intermediate fibers stained dark; $R$ fibers stained light. Bars represent $20 \mu \mathrm{m}$.

Flicker, and Pileated Woodpecker muscles (Table 1; Figs. 4F and 5G-L). As in many other bird species (Rosser and George 1986a), there was a greater percentage of $R$ fibers present in deeper sections of each woodpecker pectoralis muscle in comparison to superficial regions of the same muscle (Table 1). For example, in the middle superficial region of the Northern Flicker muscle, $69.2 \%$ of the fibers were type $R$, whereas in the middle deep region, $84.2 \%$ were type $R$. The only exception to this pattern was the lateral region of Downy Woodpecker muscle, which 

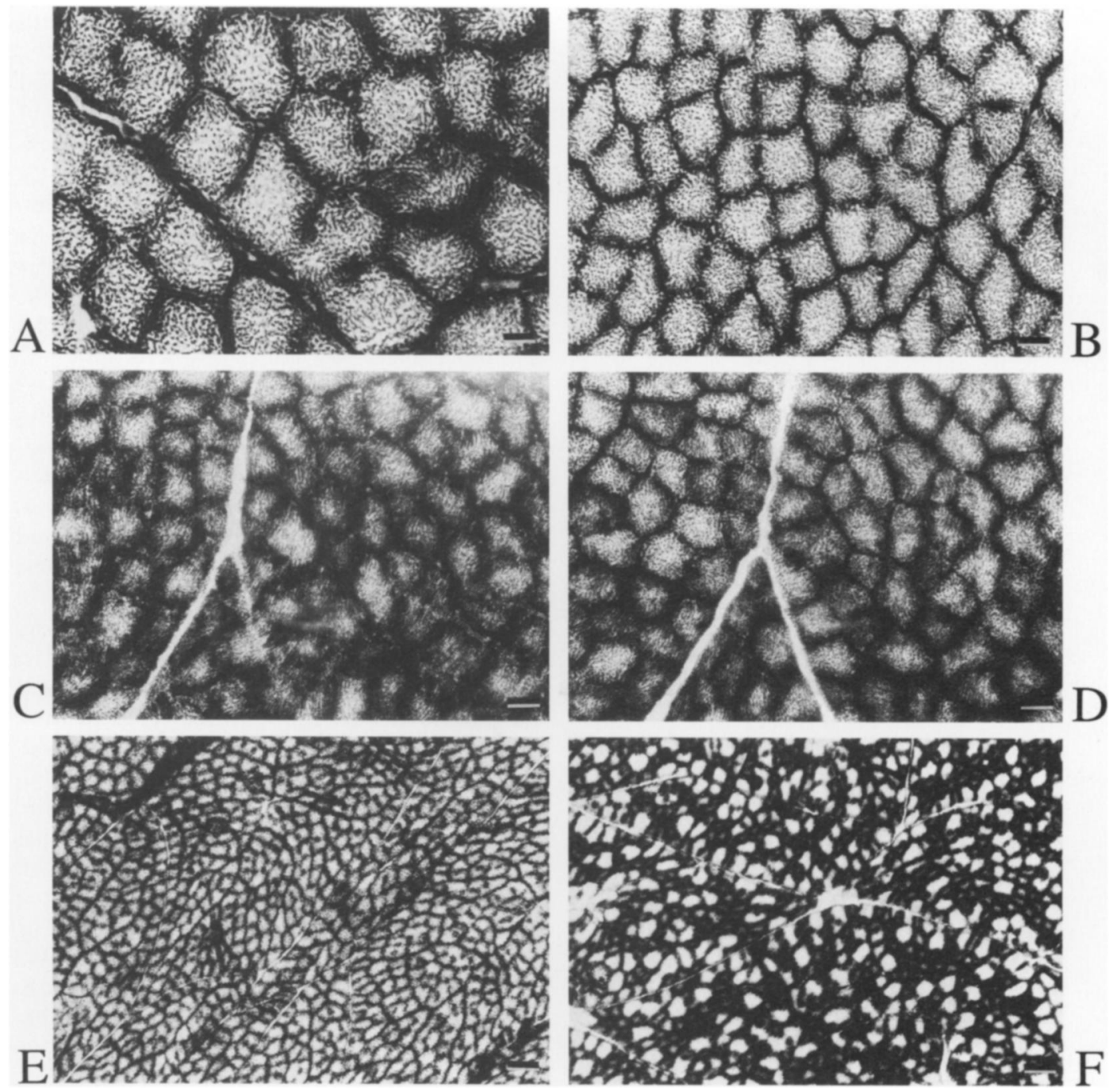

Fig. 4. Patterns of variation within and among fiber types in woodpecker pectoralis muscle. (A) Region of large-diameter $(\bar{x}=35 \mu \mathrm{m}) R$ fibers stained for SDH in medial deep region of Hairy Woodpecker muscle. (B) Small-diameter $(\bar{x}=20 \mu \mathrm{m}) R$ fibers from middle superficial region of same Hairy Woodpecker muscle shown in panel A (same magnification, also stained for SDH). Similar variation in cell diameter observed among both $I$ and $R$ fibers in pectoralis of each woodpecker species, but not consistently related to particular region of midbelly of muscle. (C) Downy woodpecker $R$ fibers, from middle superficial region, illustrating variation within fiber type for SDH staining intensity frequently observed in muscles from Downy and Hairy Woodpeckers. (D) Serial section corresponding to panel C, showing variation in GPD staining intensity within $R$ fibers. (E and F) Lower magnifications of SDH-stained transverse sections, revealing that $R$ fibers in the Red-naped Sapsucker pectoralis (E, middle deep region) were the most uniform in staining intensity among all woodpecker species, whereas contrast in staining between $I$ and $R$ fibers was greatest in pectoralis of the Pileated Woodpecker ( $F$, middle superficial region) compared to other woodpecker species. Bars in A-D represent $20 \mu \mathrm{m}$; bars in $\mathrm{E}$ and $\mathrm{F}$ represent $80 \mu \mathrm{m}$.

had almost the same number of $R$ fibers in the superficial (82.9\%) and deep (82.0\%) regions (Table 1$)$. In the regions of each species' muscle that contained both $R$ and $I$ fibers, the average percentage of $R$ fibers ranged between 62.6 and $88.0 \%$ (Table 1). For the species that had $I$ fibers in their pectoralis muscles (i.e. all except Rednaped Sapsucker), the average percentage of $I$ 


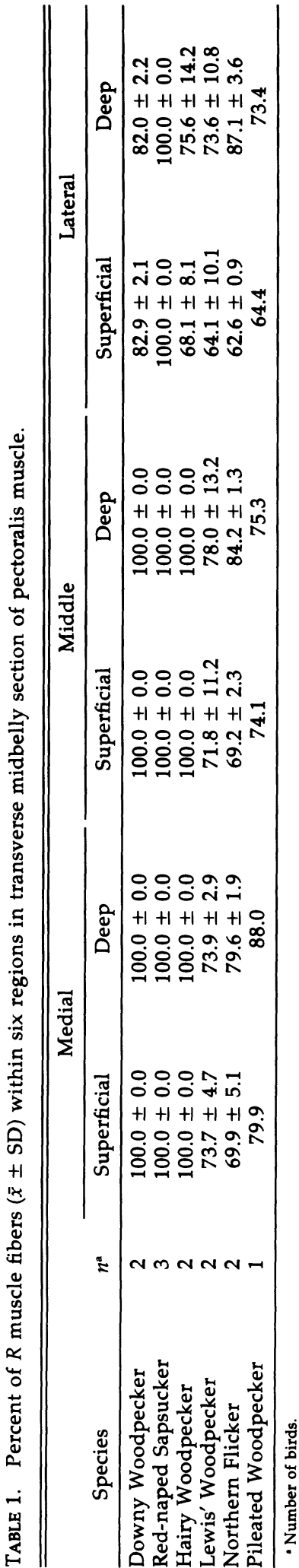

fibers scaled positively and significantly with body mass (Fig. 6A).

The average diameter of $I$ fibers increased significantly with body mass among species, but the average diameter of $R$ fibers in the woodpecker muscles did not (Table 2; Fig. 6B, C). Within the muscle of each woodpecker species, the average diameter of $I$ fibers was always greater than the average diameter of $R$ fibers (Table 2; Figs. 4F and 5A, B, G-L). For example, in the Northern Flicker, $R$ fibers averaged 28.6 $\mu \mathrm{m}$ and $I$ fibers $36.7 \mu \mathrm{m}$ in diameter (Table 2; Fig. 5I, J).

$R$ fibers in the woodpecker pectoralis muscles generally stained intensively for $\mathrm{SDH}$ and moderately for GPD, as in the Rock Dove and European Starling controls (Figs. 3-5). However, the staining characteristics for $I$ fibers differed among woodpecker species and between most woodpecker species and the type $I$ controls in the European Starling (Fig. 3E, F). In the Downy and Hairy woodpeckers, I fibers stained lighter than the $R$ fibers with SDH stain, but there was no difference between the two types in their staining for GPD (Fig. 5A, B, E, F). Lewis' Woodpecker muscle fibers (both $I$ and $R$ ) stained uniformly for SDH (Fig. 5G), but there was considerably more contrast between the two types in reaction to GPD staining: $R$ fibers were lighter and $I$ fibers stained intensively (Fig. $5 \mathrm{H}$ ), as in the European Starling control muscle (Fig. 3F). In the Northern Flicker and the Pileated Woodpecker, $I$ fibers stained lighter than $R$ fibers for both SDH and GPD (Figs. 4F and 5IL).

Morphometrics.-Pectoralis mass, wingspan, wing length, and the lengths of the sternum, furcula, coracoid, humerus, ulna, radius, manus, 8th primary, and 1st secondary (Tables 3 and 4; Fig. 7) all scaled positively with body mass and close to the predictions of geometric similarity for log-transformed variables, wherein any mass or volume scales proportional to $\left(M^{1.00}\right)$ and linear dimensions to $\left(M^{0.33}\right.$; Schimdt-Nielsen 1984). Wing area scaled proportional to $\left(M^{0.77}\right)$, which was greater than the prediction for geometric scaling of surface area (i.e. $M^{0.67}$; Tables 3 and 4; Fig. 7A). The correlation coefficients for the mass, linear, and surface-area RMA slopes ranged from 0.97 to 1.00 , indicating a strong linear association in the data (all $P<0.01, n=$ 6; Table 4; Fig. 7). The high correlation between body mass and most of the dependent morphometric variables was visually apparent in graphs 
of the regressions in which the data exhibited little scatter from the RMA regression line (Fig. 7A-D).

Aspect-ratio and wing-shape indices showed moderately negative scaling with nonsignificant correlation coefficients (Tables 3 and 4; Fig. 7E, F). The Red-naped Sapsucker had the highest aspect-ratio (5.52) and wing-shape indices (1.34) among the six species (Table 3; Fig. 7E, F). Although the Lewis' Woodpecker had the second-highest wing-shape index (1.32), the Downy Woodpecker had a slightly higher aspect-ratio index than the Lewis' Woodpecker (5.19 vs. 5.16$)$. The other species had aspect-ratio indices of 4.91 or less and wing-shape indices of 1.23 or less (Table 3; Fig. 7E, F). The wingshape indices revealed that Red-naped Sapsuckers and Lewis' Woodpeckers had slightly longer and narrower (more pointed) wings in comparison to the other species (Table 3, Fig. 7F), even though regression lines of linear wing measurements and aspect-ratio index (another index of narrowness of wing) did not clearly display such a pattern (e.g. Fig. 7B, D, E).

Field observations. - With the exception of the Lewis' Woodpecker, all of the woodpecker species regularly exhibited flap-bounding during level flight (Figs. 2A and 8). Each species would takeoff with continuous flapping for between 8 and 30 wingbeats. After the first bound, there would be cycles of flapping interspersed by bounding (Figs. 2A and 8 ) until the bird began to land whereupon it began alternating phases of wing extension (glides) with bounds (Fig. 2A). The Lewis' Woodpecker rarely exhibited this flight pattern because during flight this species often foraged for flying insects. Among about 400 flight sequences that I recorded on film or video tape at four different Lewis' Woodpecker nests, only 4 flights contained cycles of flapping and bounding that were comparable directly to the flap-bounding flights of the other woodpecker species (Figs. 8 and 9). However, roughly $15 \%$ of the Lewis' Woodpecker flights contained periods of level or ascending flight that consisted of continuous flapping (Figs. 2B and 10).

During flap-bounding flight, wing kinematics changed as a function of increasing body mass (Fig. 8). In general, the smaller species performed more wingbeats between bounds and bounds of longer duration than the larger species. However, the Lewis' Woodpecker flapped more often than any of the other species (Tables
5 and 6; Figs. 8 and 9). The $2 \mathrm{~s}$ of Lewis' Woodpecker flight presented in Figure 8 contain parts of two flapping phases, whereas at least two full cycles of a flapping phase followed by a bound are included in the same period of time for the other species.

Some similarities in wing kinematics were nonetheless apparent among species. All of the woodpeckers entered a bound phase by bringing the wingtips near the midaxis of the body during mid-upstroke and resumed flapping by elevating the wingtips above the midline of the body after a bound (Fig. 8). Within a wingbeat, wingspan was greatest during mid-downstroke when wingtip elevation approached $0 \mathrm{~cm}$ and least during mid-upstroke when wingtip elevation returned to $0 \mathrm{~cm}$. The wings in each species were drawn relatively close to the midline of the body during mid-upstroke in flapping, suggesting the use of a vortex-ring gait without lift production during upstroke (Rayner 1988, 1991). The wingtips of all species generally were brought closer to the midline of the body during bound phases than during midupstroke of flapping phases (Fig. 8), also indicating a lack of lift production by the wings during bounds. For example, during mid-upstroke of the wingbeats shown in Figure 8 for the Northern Flicker, wingspan at mid-upstroke was between 10 and $17 \mathrm{~cm}$, while wingspan during bound phases ranged from 5 to 10 cm.

Among the variables measured from flapbounding flight in woodpeckers, the number of flaps in a cycle, wingbeat frequency, duration of flapping phase, and duration of bound phase decreased with increasing body mass (Tables 5 and 6; Figs. 8 and 9A-D), whereas the percentage of cycle time spent flapping and flight speed tended to increase with body mass (Tables 5-7; Fig. 9E, F). In comparison to the RMA regression lines (Fig. 9), the Lewis' Woodpecker appeared to be unusual for its body mass in having relatively high values for the number of flaps in a cycle, duration of the flapping phase, and percent of cycle time spent flapping, and relatively low values for wingbeat frequency and flight speed. The values for this species would have been even more unusual for its body mass had I included samples of level flights with continuous flapping (e.g. Fig. 10). The Hairy Woodpecker also had a relatively high number of flaps in a cycle and wingbeat frequency for its body mass (Fig. 9A, B). Average wingbeat fre- 

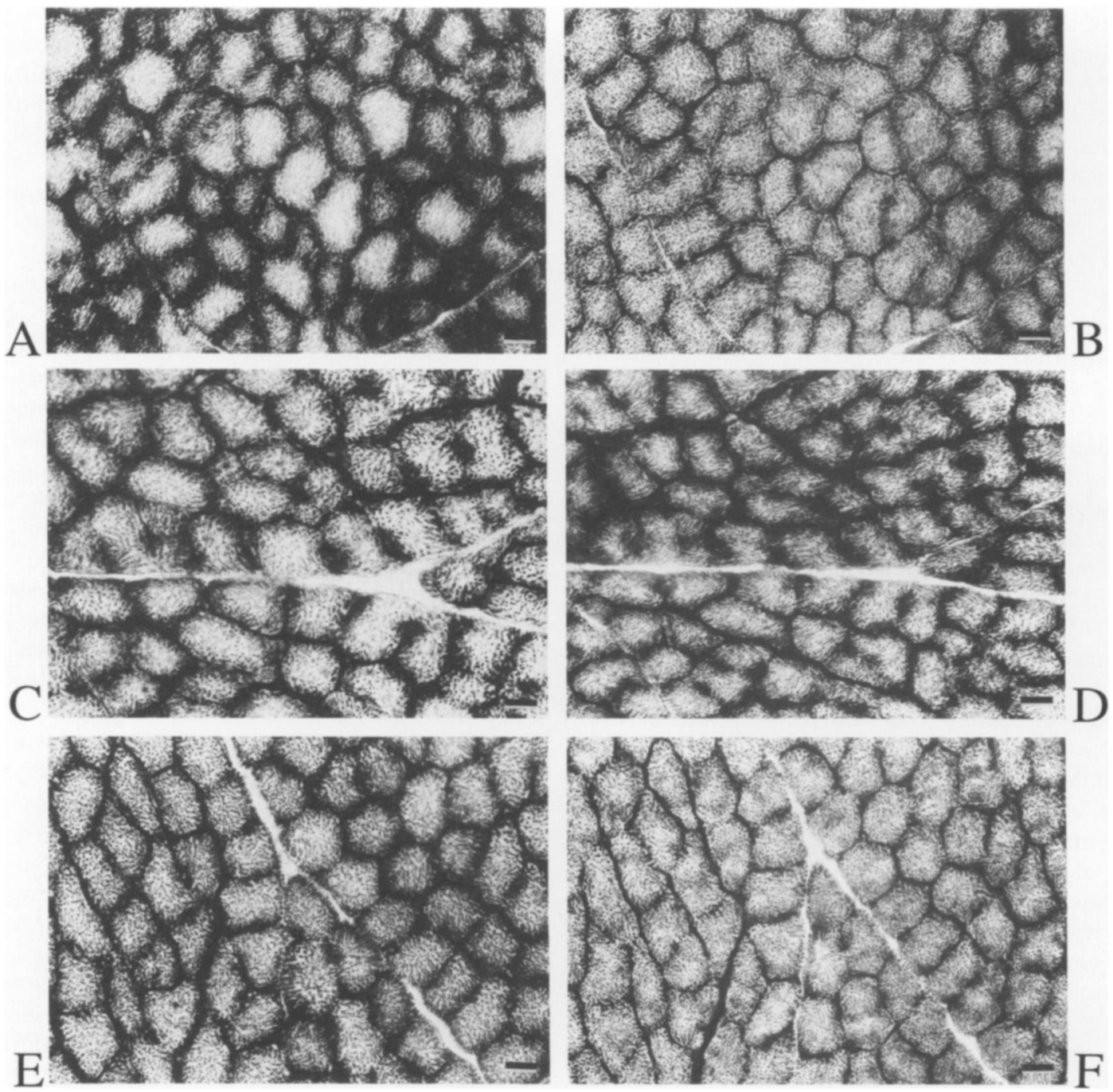

Fig. 5. Transverse serial sections of woodpecker pectoralis muscle tissue stained either for SDH (left column on page) or GPD (right). (A and B) Downy Woodpecker, lateral superficial, $R$ and $I$ fibers; (C and D) Rednaped Sapsucker, middle superficial, $R$ fibers; (E and F) Hairy Woodpecker, middle superficial, $R$ fibers; (G and $\mathrm{H}$ ) Lewis' Woodpecker, medial superficial, $R$ and $I$ fibers; (I and J) Northern Flicker, lateral superficial, $R$ and $I$ fibers; (K and L) Pileated Woodpecker, lateral superficial, $R$ and $I$ fibers. $R$ fibers always stained darker for SDH than I fibers, except in pectoralis of Lewis' Woodpecker, wherein both fiber types stained similarly for SDH, but $I$ fibers stained much darker than $R$ fibers for GPD. Bars represent $20 \mu \mathrm{m}$.

quency in the Hairy Woodpecker was $12.2 \mathrm{~Hz}$ compared to $10.3 \mathrm{~Hz}$ in the lighter-weight Rednaped Sapsucker (Table 5; Fig. 9B).

Excluding the Lewis' Woodpecker from the sample improved the fit of RMA regression lines to the data for all of the variables except for wingbeat frequency and duration of bounding phase (Fig. 9). With the Lewis' Woodpecker included in the sample, only the correlation co- efficients for wingbeat frequency and duration of bounding phase were statistically significant (Fig. 9), but excluding this species increased the correlations so that the coefficients for the number of flaps in a cycle, wingbeat frequency, duration of flapping phase, and duration of bounding phase were significant $(P<0.05)$.

The RMA regressions and correlation coefficients describing the scaling of intermittent 

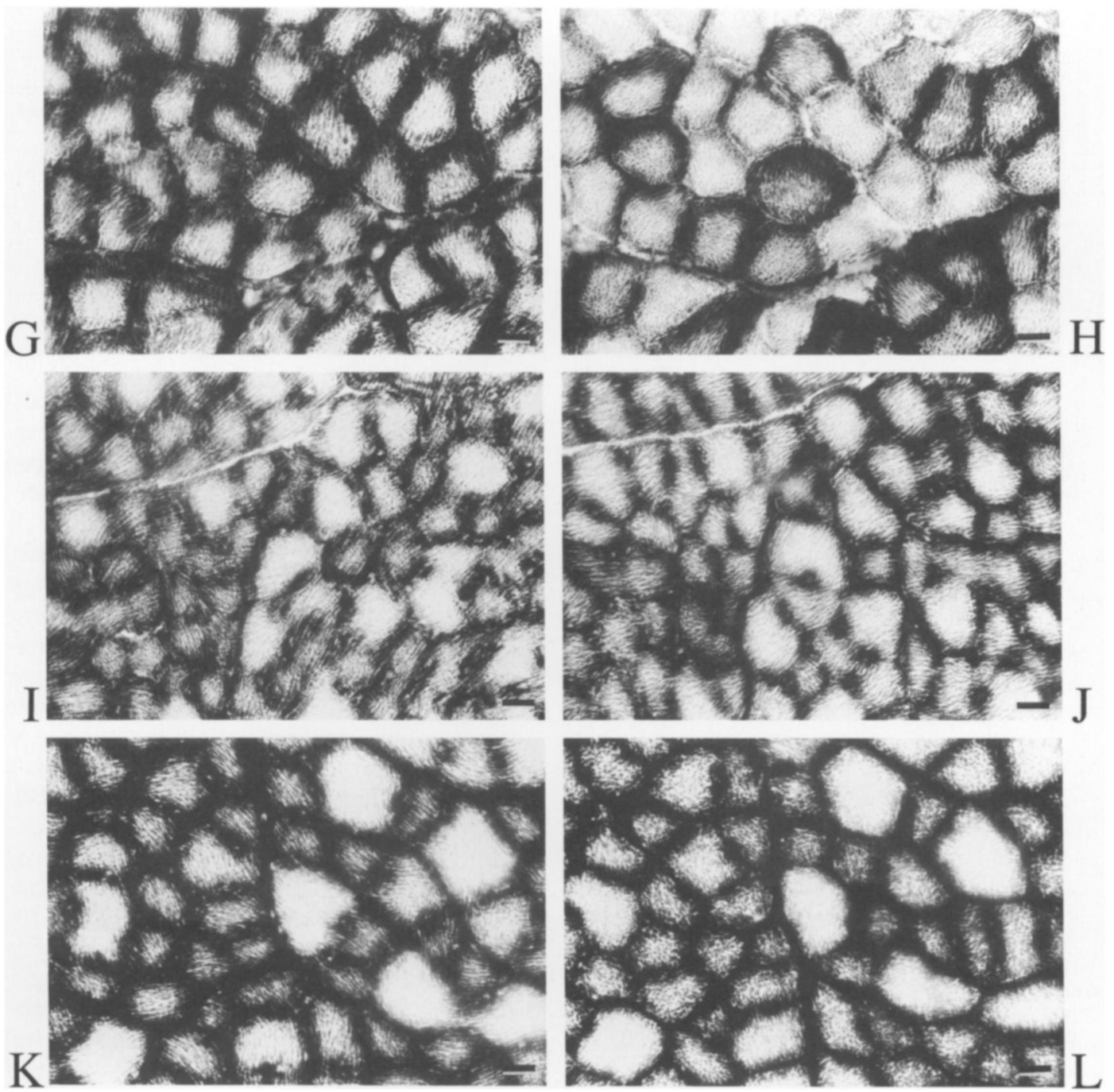

Fig. 5. Continued.

flight variables in Figure 9 were computed with the Lewis' Woodpecker excluded $(n=5)$. For comparison, with this species included in the sample $(n=6)$, the scaling formulas, correlation coefficient, and probability values for the statistical significance of the correlation coefficients were: $\log$ number of flaps in cycle $(y=$ $-0.87 x+2.26, r=-0.72, P=0.11), \log$ wingbeat frequency $(y=-0.49 x+1.86, r=-0.81$, $P=0.05), \log$ duration of flapping phase $(y=$ $-0.82 x+4.22, r=0.28, P=0.58), \log$ duration of bounding phase $(y=-0.82 x+3.93, r=0.87$, $P=0.02), \log$ percent of cycle spent flapping ( $y$ $=0.25 x+1.32, r=0.53, P=0.29)$, and log flight speed $(y=0.14 x+0.68, r=0.26, P=0.61)$.
The means for the field variables exhibited relatively small standard deviations among geographic locations (i.e. sampling units) within a species (Tables 5 and 7), but among all of the cycles observed in each species the behaviors showed considerable variation (Tables 6 and 7; Fig. 8). For example, Northern Flickers flapped on average 1.9 times during a cycle (Table 5), but this variable ranged from one to seven flaps in the 153 cycles observed (Table 6). During the $2 \mathrm{~s}$ of intermittent flight in a Northern Flicker shown in Figure 8, the number of wingbeats between bounds ranged from one to four. Flight speed in the Lewis' Woodpecker provides another example of the considerable variability in 

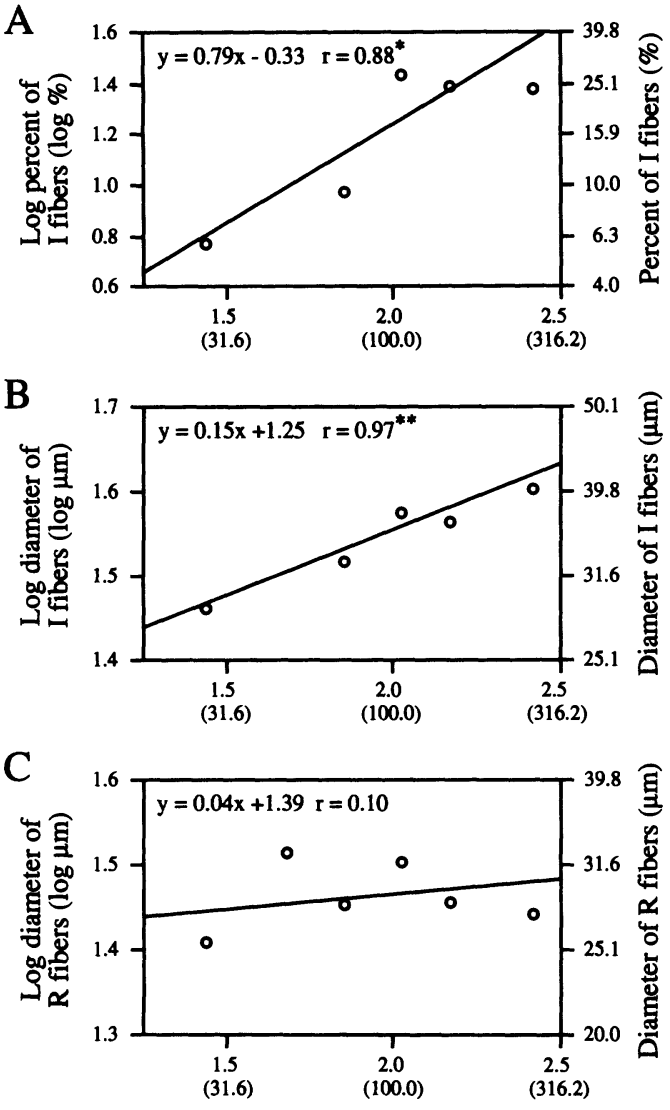

Log body mass (log g)

(Body mass [g])

Fig. 6. RMA regressions and correlation coefficients $(r)$ describing relationships between $l o g$ of variables measured from histological sections of pectoralis muscle and log body mass for (in order of increasing body mass): Downy Woodpecker, Red-naped Sapsucker, Hairy Woodpecker, Lewis' Woodpecker, Northern Flicker, and Pileated Woodpecker. (A) Percent of $I$ fibers in pectoralis muscle (excluding Rednaped Sapsucker which had only $R$ fibers). (B) Average minimum cross-sectional diameter $(\mu \mathrm{m})$ of $I$ fibers (excluding Red-naped Sapsucker). (C) Average minimum cross-sectional diameter $(\mu \mathrm{m})$ of red $(R)$ fibers. ${ }^{*} P<0.05,{ }^{*} P<0.01$.

behavior within birds (Table 7). Among three independent locations, the average flight speed was $7.3 \pm 0.2 \mathrm{~m} / \mathrm{s}$, whereas among the 12 flights for which I measured flight speed in this species, speed ranged from 4.7 to $11.0 \mathrm{~m} / \mathrm{s}$ (Table 7).

Flycatching.-Lewis' Woodpeckers commonly engaged in foraging flights during which they caught insects in the air (Figs. 2B and 10).
TABLE 2. Minimum cross-sectional diameter $(\bar{x} \pm$ SD) of $R$ and $I$ muscle fibers in midbelly transverse sections of pectoralis muscle.

\begin{tabular}{lccc}
\hline \hline \multicolumn{1}{c}{ Species } & $n^{\mathrm{a}} R$ fiber $(\mu \mathrm{m})$ & $I$ fiber $(\mu \mathrm{m})$ \\
\hline Downy Woodpecker & 2 & $25.7 \pm 0.2$ & $28.9 \pm 2.6$ \\
Red-naped Sapsucker & 3 & $32.6 \pm 0.8$ & Not present \\
Hairy Woodpecker & 2 & $28.4 \pm 2.1$ & $33.0 \pm 6.7$ \\
Lewis' Woodpecker & 2 & $31.8 \pm 0.4$ & $37.7 \pm 0.1$ \\
Northern Flicker & 2 & $28.6 \pm 2.2$ & $36.8 \pm 3.4$ \\
Pileated Woodpecker & 1 & 27.7 & 40.2 \\
\hline
\end{tabular}

- Number of birds.

These flights included changes in altitude, maneuvering, and extended glides (up to $10 \mathrm{~s}$ in duration). Considerable temporal variation, beyond the scope of the present study, was evident in their flycatching behavior (see Bock 1970). A typical foraging flight would consist of continuous flapping after takeoff (from a tree or pole) until an insect was captured. The bird would then glide and occasionally flap or maneuver its wings asymmetrically to catch or pursue another insect. The return to a perch (either a tree or a pole) consisted of alternating glides and bounds that were similar to the landings I observed in other woodpeckers (Figs. 2 and 10).

The wing kinematics for a Lewis' Woodpecker during a brief foraging flight (Fig. 10) provide an example of flycatching behavior for the species. During the first 4,200 ms in Figure 10, the bird flapped continuously, flew directly away from the tree from which it took off, and looked both left and right several times-probably scanning for insects in the air. Between $4,200 \mathrm{~ms}$ and $4,900 \mathrm{~ms}$, it banked slightly to the right in pursuit of an insect, and it changed wingbeat gait (from a vortex-ring gait towards continuous-vortex gait; Rayner 1988, 1991) by increasing wingspan during mid-upstroke in comparison to the previous 32 wingbeats. This change in wingbeat gait probably represented deceleration. At 5,000 ms, the bird began a complex series of asymmetric wing and tail movements (flexing and rotating) and banked sharply to the right until $5,200 \mathrm{~ms}$ when it captured an insect. After ingesting the insect at $5,200 \mathrm{~ms}$, the bird entered a glide and gradually banked to the right until its flight direction was toward the tree from which it took off. At $6,600 \mathrm{~ms}$, it briefly decreased its wingspan, probably with a decrease in altitude, and then resumed gliding with only one slight decrease in wingspan until $7,900 \mathrm{~ms}$. From 7,900 to $9,000 \mathrm{~ms}$, it engaged in 


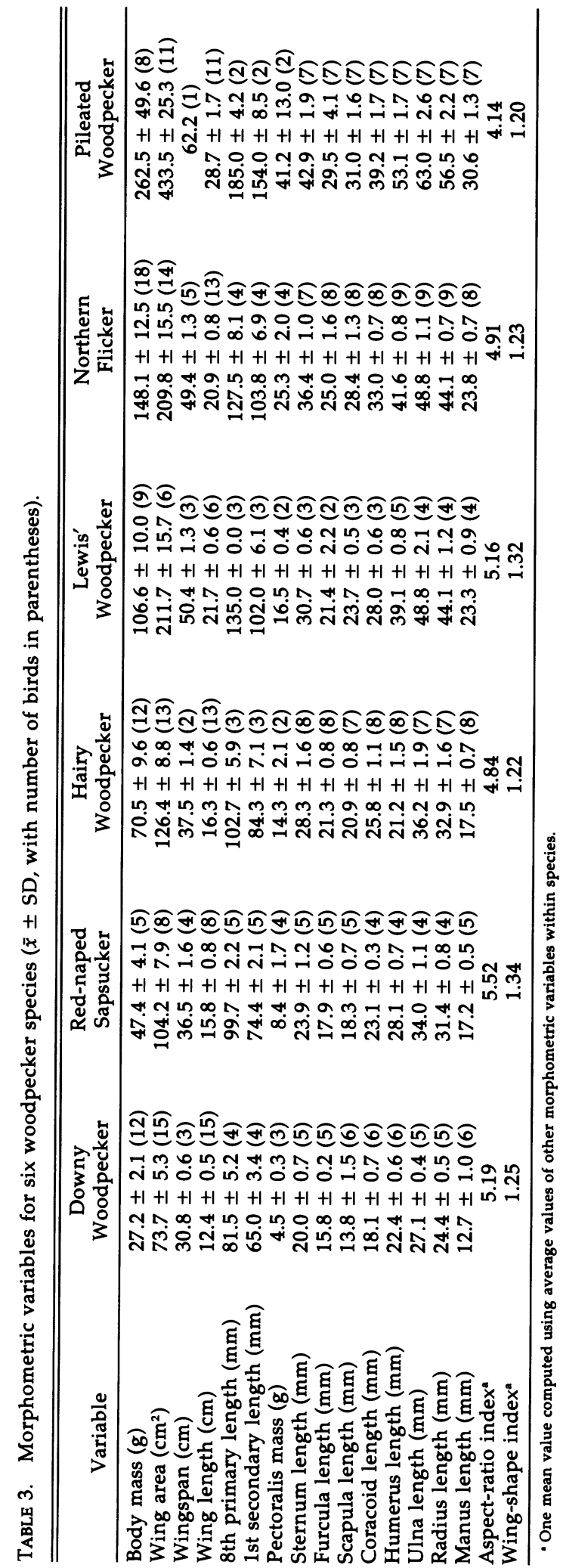


TABLE 4. Reduced-major-axis(RMA) regression slopes and correlation coefficients $(r)$ describing relationships between log of morphometric variables and $\log$ body mass for six woodpecker species.

\begin{tabular}{lcc}
\hline \hline \multicolumn{1}{c}{ Variable } & RMA & $r$ \\
\hline Wing area & 0.77 & $0.98^{* *}$ \\
Wingspan & 0.32 & $0.98^{* *}$ \\
Wing length & 0.36 & $0.98^{* *}$ \\
8th primary length & 0.35 & $0.97^{* *}$ \\
1st secondary length & 0.37 & $0.98^{* *}$ \\
Pectoralis mass & 0.97 & $0.99^{* *}$ \\
Sternum length & 0.34 & $1.00^{* *}$ \\
Furcula length & 0.27 & $0.99^{* *}$ \\
Scapula length & 0.36 & $0.99^{* *}$ \\
Coracoid length & 0.33 & $0.99^{* *}$ \\
Humerus length & 0.38 & $0.98^{* *}$ \\
Ulna length & 0.38 & $0.99^{* *}$ \\
Radius length & 0.37 & $0.98^{* *}$ \\
Manus length & 0.38 & $0.98^{* *}$ \\
Aspect-ratio index & -0.13 & 0.77 \\
Wing-shape index & -0.06 & 0.42 \\
\hline
\end{tabular}

$* *=P<0.01$

glide-bounding, which it continued afterwards until landing.

The Red-naped Sapsucker was the only other species I observed to use flycatching flights. I successfully recorded two examples of flycatching at one Red-naped Sapsucker nest, and the wing kinematics during a portion of one of these are presented in Figure 11. The Red-naped Sapsucker began a flycatching sally using continuous flapping as in the Lewis' Woodpecker (Figs. 2B, and 10), but the Red-naped Sapsucker exhibited intermittent bounds, rather than prolonged glides, after insect capture (Fig. 11). The successful capture of an insect generally occured during a bound with the wings only partially flexed. The wingspan was near $10 \mathrm{~cm}$ at insect capture in Figure 11, whereas during the subsequent bound that occured after 1 wingbeat, wingspan was approximately $5 \mathrm{~cm}$.

\section{Discussion}

Among the six species of woodpeckers included in this study, there was an effect of body size on almost all variables examined. Important observations include that the Pileated Woodpecker used flap-bounding flight (Tables 5 and 6; Figs. 8 and 9) in spite of being considerably greater in body mass than the expected limit for this behavior (Rayner 1977, 1985a, DeJong 1983). Also, the unusual flight behavior of the Lewis' Woodpecker, relative to the other species (Tables 5 and 6; Figs. 2, 8-10), was more closely related to differences in muscle composition (Fig. 5) and flight speed (Table 7; Fig. 9F) than to differences in wing design (Fig. 7).

Functional interpretation of muscle composition.-The results from histological staining of pectoralis muscles were consistent with the basic premise of the fixed-gear hypothesis that the heterogeneity of muscle composition should scale positively with body mass (Goldspink 1977, 1981 , Rayner 1977, 1985a). If the assumption is correct that $R, I$, and $W$ fibers represent different functional groups of avian fast-twitch skeletal muscle with progressively increasing optimal contractile velocities (George and Berger 1966, Rosser and George 1986a, Norberg 1990), the smaller woodpecker species had pectoralis muscles of more uniform contractile properties than those of the species larger than $100 \mathrm{~g}$ (Tables 1 and 2; Figs. 4E, F, 5, and 6). This conclusion is consistent with prior study of woodpecker muscle tissue (George and Berger 1966). The Yellow-fronted Pied Woodpecker (Dendropicos mahratta; body mass 34g; Dunning 1993), has only $R$ fibers, but the pectoralis in Goldenbacked Woodpeckers (Dinopium benghalense; body mass $100 \mathrm{~g}$; Dunning 1993) contains $27.8 \%$ $R$ fibers and $72.2 \%$ I fibers (George and Berger 1966). However, as noted by Rosser and George (1986a), inferring function from histological stains requires caution because the contractile properties of avian fiber types have not been rigorously tested as for some species of mammals (e.g. Sweeney et al. 1986).

Dark, or intense staining for either SDH or GPD suggests that a fiber has well-developed oxidative or glycolyitic capacity, respectively. These physiological properties may be related to contractile properties of the muscle fiber, given that high oxidative capacity tends to be associated with large numbers of mitochondria, fatigue resistance, and slower contractile velocity, whereas high glycolytic capacity tends to be associated with low mitochondrial density, low endurance, and fast contractile velocity (George and Berger 1966, Goldspink 1977, 1981, Loeb and Gans 1986, Rosser and George 1986a, b, Hermanson and Foehring 1988, Norberg 1990). In addition, fiber diameter tends to be positively correlated with contractile velocity. Thus, variation in staining intensity and fiber diameter between $R$ and $I$ fibers (e.g. Fig. 4F) likely represented functional differences in contractile properties. Considerable differences 

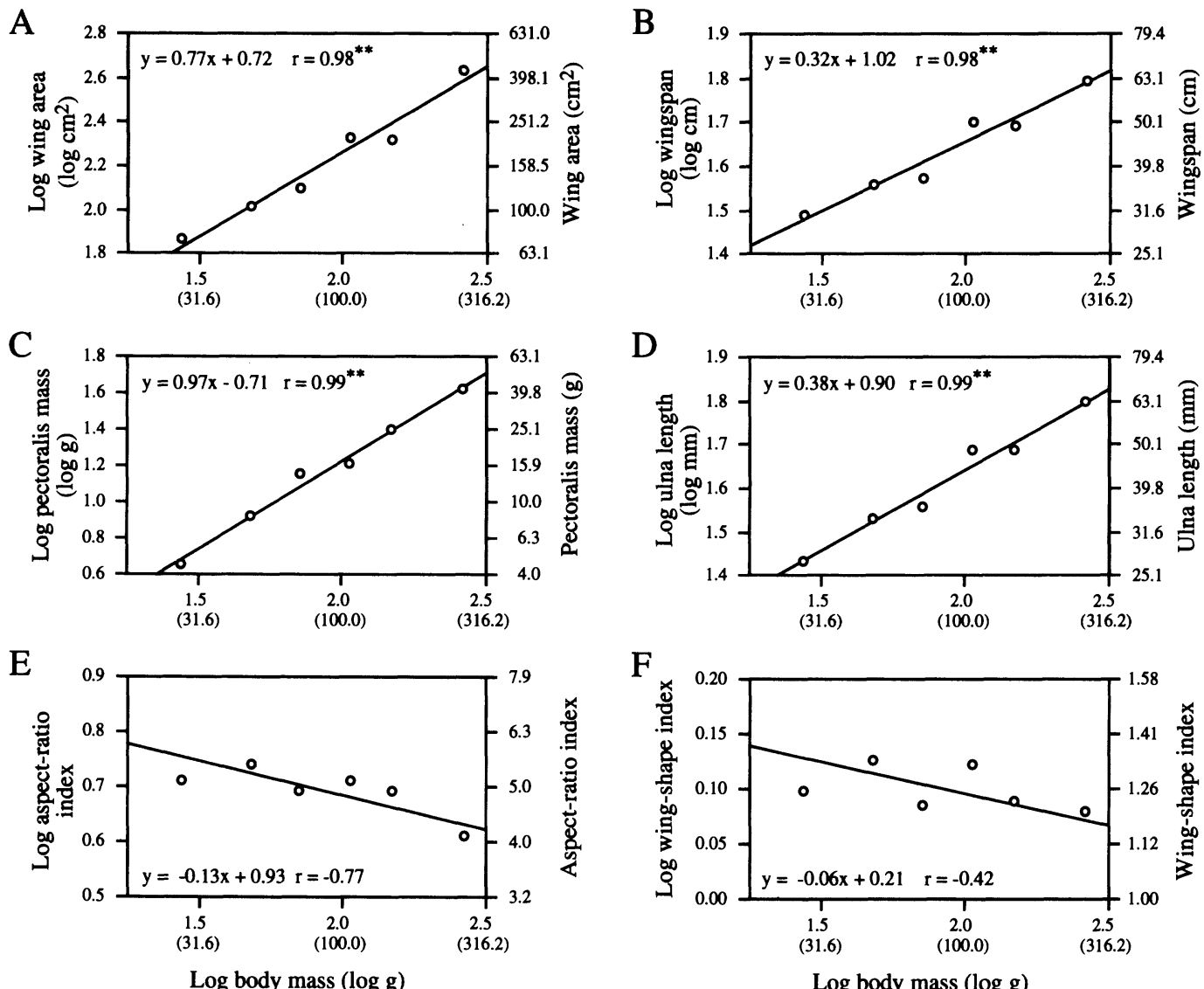

Log body mass $(\log \mathrm{g})$

(Body mass [g])

(Body mass [g])

Fig. 7. RMA regressions and correlation coefficients $(r)$ describing relationships between log of selected morphometric variables and log body mass for (in order of increasing body mass): Downy Woodpecker, Rednaped Sapsucker, Hairy Woodpecker, Lewis' Woodpecker, Northern Flicker, and Pileated Woodpecker. (A) Wing area (single wing, $\mathrm{cm}^{2}$ ); (B) wingspan (cm); (C) pectoralis mass (both sides combined, $\mathrm{g}$ ); (D) ulna length $(\mathrm{mm}) ;(\mathrm{E})$ aspect-ratio index; and $(\mathrm{F})$ wing-shape index. ${ }^{* *} P<0.01$.

in staining or diameter within fiber types within species (Fig. 4A-D) indicated that this variation, in some cases, may be best described as a continuum rather than as discrete categories. Differences in GPD staining for I fibers among species (Fig. 5) further illustrated the potential for variation within a single avian fiber type.

The $I$ fibers in the Northern Flicker and the Pileated Woodpecker appeared to have relatively low oxidative and glycolytic capacity, as indicated by light staining for both SDH and GPD (Fig. 5I-L). What are these fibers using as an energy source to fuel contraction? My study does not offer a ready answer. Similar lightstaining for both oxidative and glycolytic capacity is observed in distal wing muscles of the
Rock Dove (George and Berger 1966), but this pattern was unlike the staining in $I$ fibers in the European Starling pectoralis, or $W$ fibers in the Rock Dove pectoralis, in which glycolytic capacity was high and oxidative capacity was low (Fig. 3C-F). Possibly, crystal formation during histological staining is localized in different regions of $I$ and $W$ fibers, depending on the species or even the muscle within a species; resolution of this issue awaits further study.

The I muscle fibers in the Lewis' Woodpecker pectoralis were the only type $I$ woodpecker muscle fibers to stain dark for GPD as in the European Starling control (Figs. 3F, and 5H). This could represent a physiological correlate with the periods of continuous flapping and 

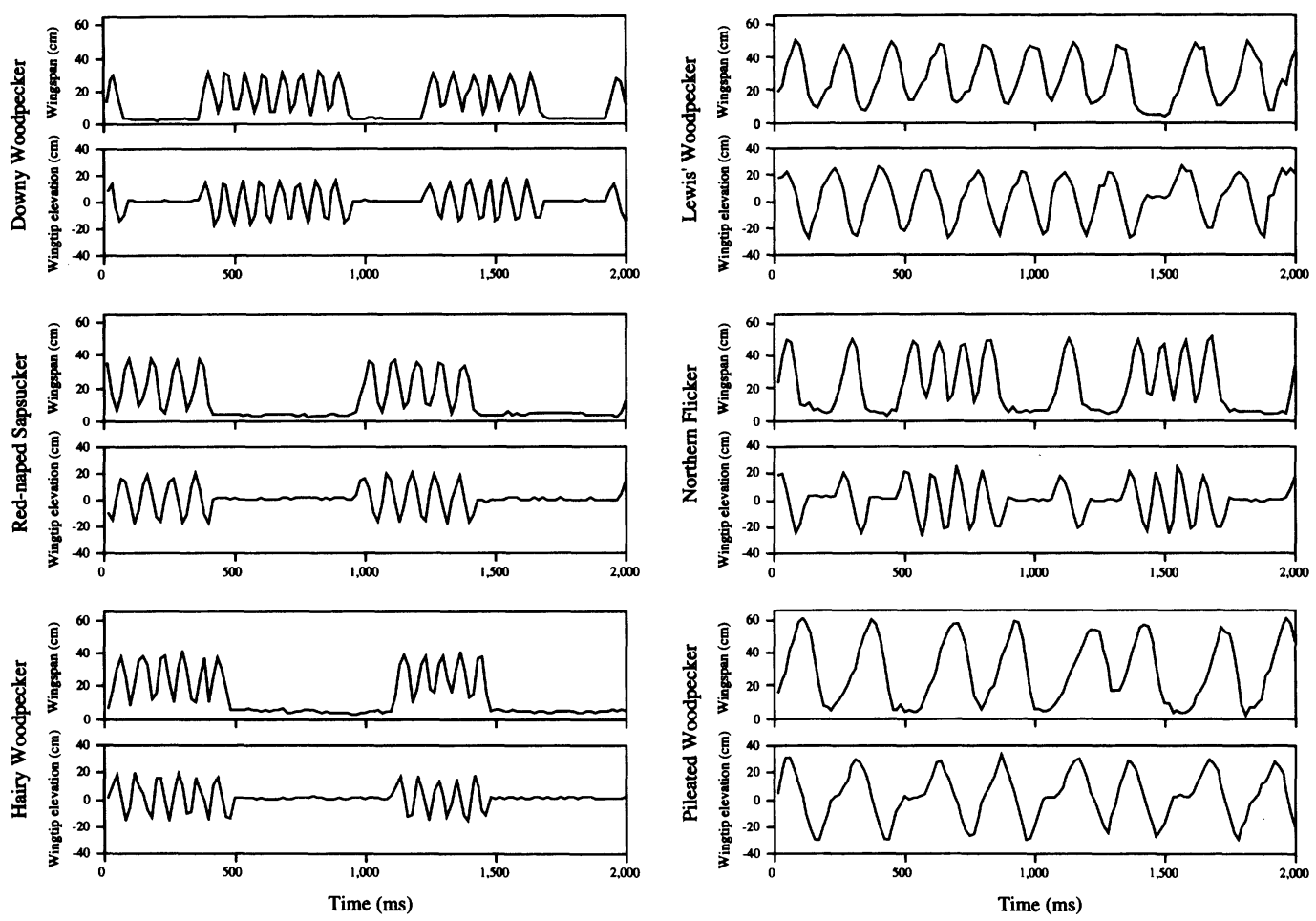

Fig. 8. Wingspan and wingtip elevation during $2 \mathrm{~s}$ of intermittent (flap-bounding) flight for (in order of increasing body mass): Downy Woodpecker, Red-naped Sapsucker, Hairy Woodpecker, Lewis' Woodpecker, Northern Flicker, and Pileated Woodpecker. Bounds represented by phases of no wing movement lasting 50 ms or more. During wingbeats, wingspan greatest at mid-downstroke and least at mid-upstroke, and wingtip elevation reached positive peak during upstroke/downstroke transition and negative peak at downstroke/ upstroke transition. All species entered bound phases during mid-upstroke and resumed flapping with continuation of upstroke. Portions of two or more complete cycles (consisting of flapping phase followed by bound) shown for all except for Lewis' Woodpecker, which often flapped continuously for extended periods of level flight. Sequence for Lewis' Woodpecker contains parts of two flapping phases that both lasted longer than $2 \mathrm{~s}$.

frequent, prolonged glides that occur during foraging flights in the Lewis' Woodpecker (Figs. 2B and 10). The European Starling adopts glide postures proportionally more often and for longer time periods during nonflapping phases than either bounds or flexed-wing partial glides (Tobalske 1995). Perhaps the larger-diameter, more-glycolytic I fibers in the pectoralis of the Lewis' Woodpecker are recruited during continuous flapping phases of foraging and then turned off during glides, when alternative motor units consisting of $R$ fibers are selectively recruited.

The Lewis' Woodpecker muscle fibers also appeared more rounded and "loosely packed" in comparison to the fibers in the other species (Fig. 5). This rounded-fiber appearance is ap- parently typical of birds that engage in extended gliding behavior (George and Berger 1966, Rosser and George 1986a). Rosser and George (1986a) suggested the functional explanation for this appearance is that there is less fiber density per unit cross-sectional area in the muscles of gliding birds because less force is generated during glides than during flapping. However, the Lewis' Woodpecker, like the other woodpecker species (Fig. 3A), did not exhibit slowtwitch fibers in its pectoralis. Slow-twitch fibers would be highly economical during prolonged glides (Goldspink 1977, Rayner 1977, 1985a, Rosser and George 1986a).

The association between body mass and I fibers in the pectoralis may help explain why woodpecker species up to almost $300 \mathrm{~g}$ in body 
A

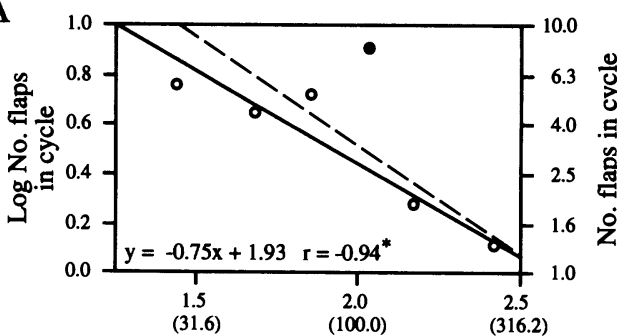

$\mathrm{C}$

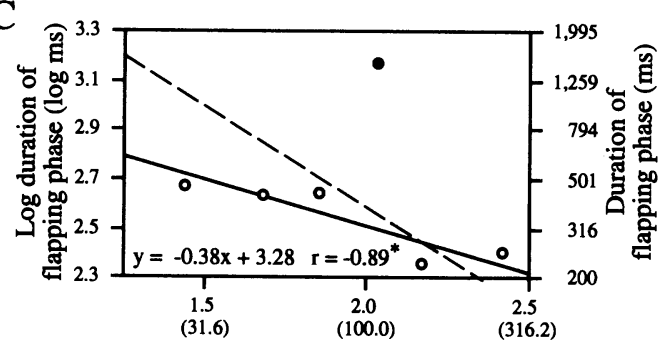

$\mathrm{E}$

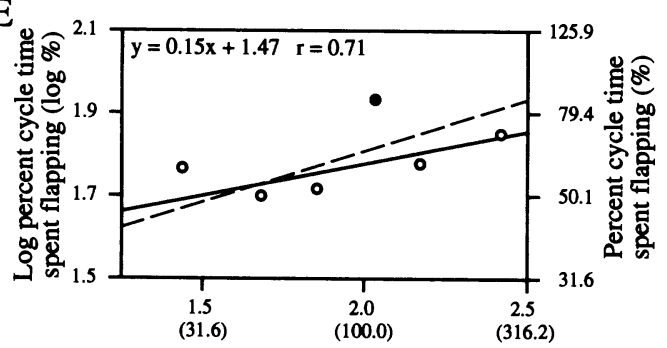

Log body mass (log g)

(Body mass [g])
B

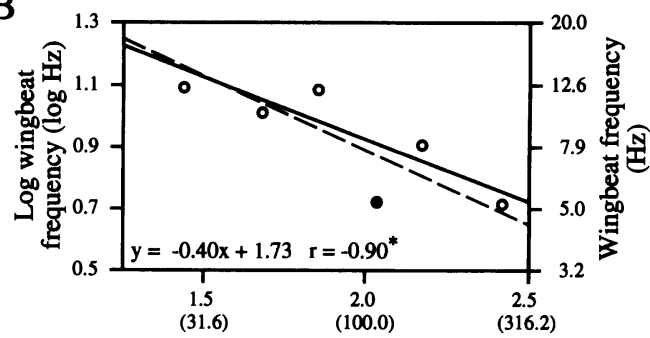

D

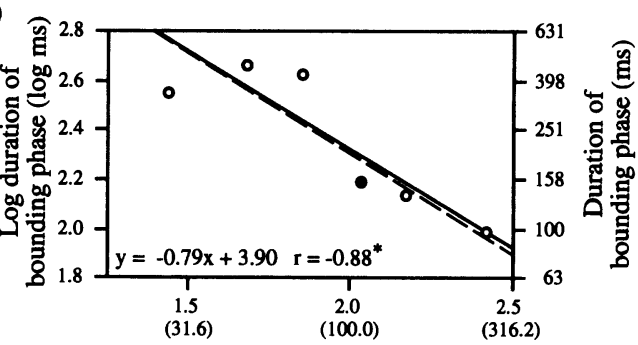

$F$

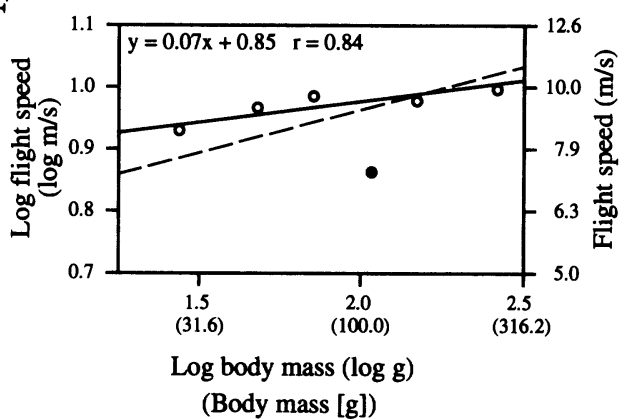

Fig. 9. RMA regressions and correlation coefficients $(r)$ describing the relationships between log of variables measured from flap-bounding flight and log body mass for (in order of increasing body mass): Downy Woodpecker, Red-naped Sapsucker, Hairy Woodpecker, Lewis' Woodpecker, Northern Flicker, and Pileated Woodpecker. Filled circles denote Lewis' Woodpecker. RMA regressions and correlation coefficients computed with this species excluded from sample (solid lines, formulas, and $r$ as shown) or included (dashed line, see text for formulas and $r$ ). (A) number of flaps in cycle; (B) wingbeat frequency (during flapping phase only, $\mathrm{Hz}$ ); (C) duration of flapping phase (ms); (D) duration of bounding phase (ms); (E) percent of cycle time spent flapping (\%); and (F) flight speed $(\mathrm{m} / \mathrm{s}){ }^{*}, P<0.05$

mass used flap-bounding flight (Tables 5 and 6; Figs. 8 and 9) when previous theory and empirical observations (Rayner 1977, 1985a, DeJong 1983) indicated that there should be a limit near $100 \mathrm{~g}$ in body mass for the ability to regularly perform intermittent bounds. Positive scaling relationships for the percent and crosssectional diameter of $I$ fibers have not previously been reported for birds (George and Berger 1966, Rosser and George 1986a, Norberg 1990; Tables 1 and 2; Figs. 4E, F, 5, and 6). The cross-sectional diameter of $R$ fibers did not change significantly with body mass (Table 2;
Fig. 6), which lends support to the assumption that the two fiber types function differently in active avian muscle.

The prediction of a size limit for the ability to flap-bound assumes that stress (force production per unit cross-sectional area) and strain (change in length divided by initial length of muscle) are independent of body mass, as might reasonably be expected for birds with pectoralis muscles composed of only one fiber type (Rayner 1977, 1985a, DeJong 1983). However, alternative fiber types are expected to exhibit different optimal stress and strain values, which 

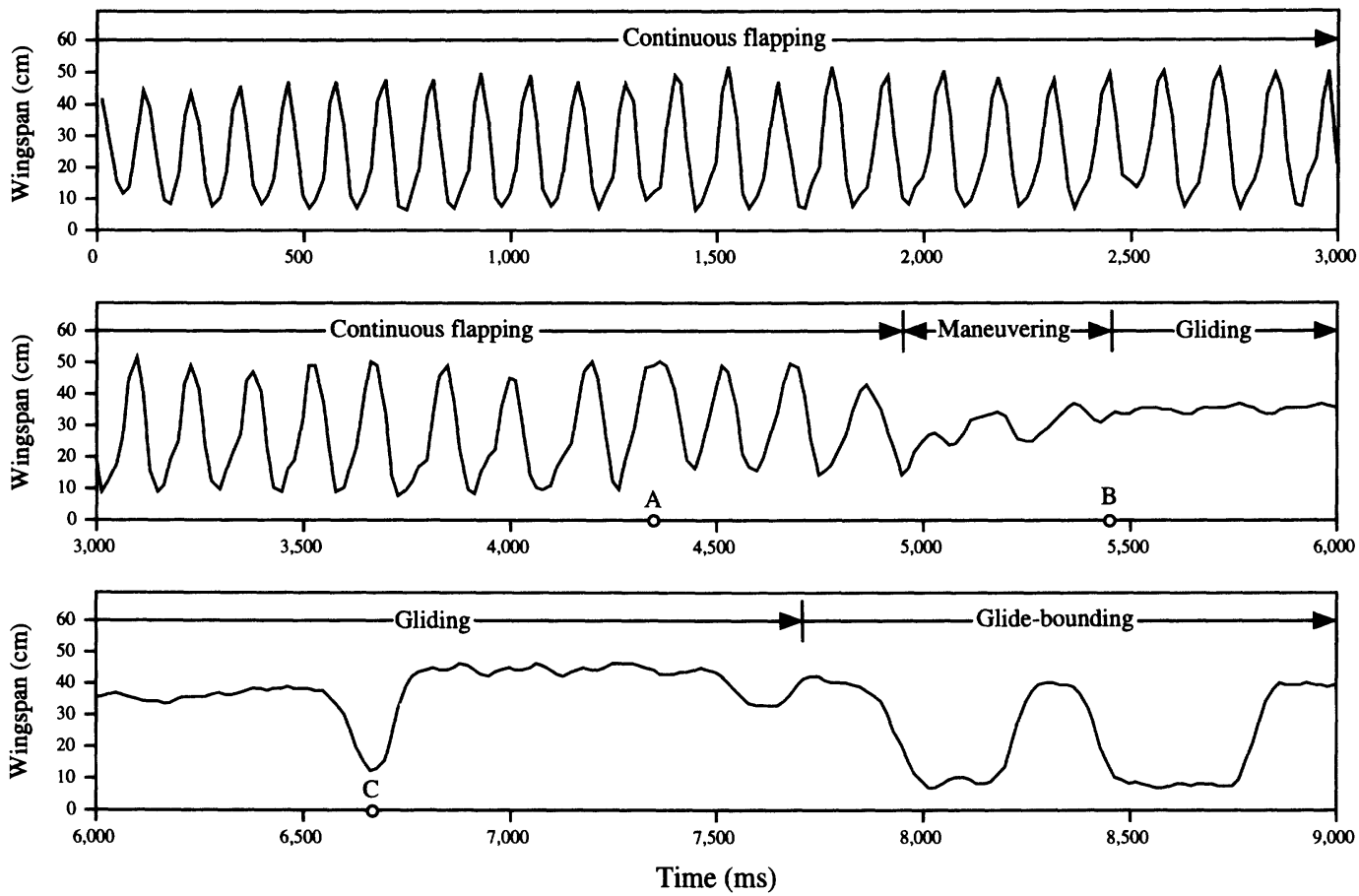

Fig. 10. Example of flycatching flight in a Lewis' Woodpecker based on $9 \mathrm{~s}$ of kinematic data representing wingspan as viewed from directly below bird. Entire flight shown except for about 500 ms immediately after takeoff from top of tree (continuous flapping) and about 1,000 ms before landing on top of same tree (glidebounding to landing); overall change in altitude was $5 \mathrm{~m}$ or less. During wingbeats, maximum wingspans mark mid-downstroke; minimum spans mark mid-upstroke. Open circles on time axis correspond to following: (A) bird started to use different wingbeat gait, identified by increased wingspan at mid-upstroke, probably associated with deceleration (Rayner, 1988, 1991); (B) insect was ingested; and (C) bird flexed its wings momentarily during glide, and probably decreased slightly in altitude.

could alter the predicted slopes for the scaling of available mass-specific power from the flight muscles (Ellington 1991, Marden 1994). In woodpeckers then, larger-diameter $I$ fibers in the pectoralis may generate greater stress and strain (thus, greater power) during contraction than smaller-diameter $R$ fibers, providing a mechanism for offsetting the predicted adverse scaling of both sustainable power and acceleration ability with body mass. DeJong's (1983) prediction of a size limit for flap-bounding was based on empirical study of acceleration ability primarily in passerine species, with the only nonpasserine being the Northern Flicker. It may be that muscle composition in passerines scales differently than in woodpeckers, with associ-

TABLE 5. Intermittent flight variables $(\bar{x} \pm \mathrm{SD})$ measured from flapping/nonflapping cycles.

\begin{tabular}{|c|c|c|c|c|c|c|}
\hline \multirow[b]{2}{*}{ Species } & \multirow[b]{2}{*}{$n^{\mathrm{a}}$} & \multirow[b]{2}{*}{$\begin{array}{l}\text { No. } \\
\text { flaps }\end{array}$} & \multirow{2}{*}{$\begin{array}{c}\text { Wingbeat } \\
\text { frequency } \\
(\mathrm{Hz})\end{array}$} & \multicolumn{2}{|c|}{ Duration of } & \multirow{2}{*}{$\begin{array}{c}\text { Percent cycle } \\
\text { time spent } \\
\text { flapping }(\%)\end{array}$} \\
\hline & & & & $\begin{array}{l}\text { Flapping } \\
\text { phase (ms) }\end{array}$ & $\begin{array}{l}\text { Bounding } \\
\text { phase (ms) }\end{array}$ & \\
\hline Downy Woodpecker & 2 & $5.8 \pm 0.7$ & $12.4 \pm 0.1$ & $469.6 \pm 37.1$ & $353.5 \pm 107.1$ & $58.4 \pm 5.6$ \\
\hline Red-naped Sapsucker & 3 & $4.5 \pm 0.3$ & $10.3 \pm 0.5$ & $434.8 \pm 5.7$ & $456.8 \pm 202.5$ & $50.5 \pm 11.5$ \\
\hline Hairy Woodpecker & 1 & 5.3 & 12.2 & 440.6 & 421.6 & 52.2 \\
\hline Lewis' Woodpecker & 3 & $8.1 \pm 1.6$ & $5.3 \pm 0.3$ & $1,484.8 \pm 271.4$ & $154.3 \pm 70.1$ & $85.8 \pm 5.6$ \\
\hline Northern Flicker & 5 & $1.9 \pm 0.3$ & $8.1 \pm 0.4$ & $227.1 \pm 34.3$ & $137.7 \pm 45.4$ & $60.5 \pm 6.6$ \\
\hline Pileated Woodpecker & 5 & $1.3 \pm 0.2$ & $5.2 \pm 0.4$ & $253.4 \pm 43.5$ & $96.6 \pm 24.4$ & $71.4 \pm 6.4$ \\
\hline
\end{tabular}

- Number of nests or independent geographic locations. 
TABLE 6. Ranges for intermittent flight variables measured from flapping/nonflapping cycles.

\begin{tabular}{|c|c|c|c|c|c|c|}
\hline \multirow[b]{2}{*}{ Species } & \multirow[b]{2}{*}{$n^{\mathrm{a}}$} & \multirow[b]{2}{*}{$\begin{array}{l}\text { No. } \\
\text { flaps }\end{array}$} & \multirow{2}{*}{$\begin{array}{l}\text { Wingbeat } \\
\text { frequency } \\
\quad(\mathrm{Hz})\end{array}$} & \multicolumn{2}{|c|}{ Duration of } & \multirow{2}{*}{$\begin{array}{c}\text { Percent cycle } \\
\text { time spent } \\
\text { flapping }(\%)\end{array}$} \\
\hline & & & & $\begin{array}{l}\text { Flapping } \\
\text { phase (ms) }\end{array}$ & $\begin{array}{l}\text { Bounding } \\
\text { phase (ms) }\end{array}$ & \\
\hline Downy Woodpecker & 32 & $2-17$ & $10-15$ & $166.6-1,150.0$ & $150.0-1,450.0$ & $30.3-86.3$ \\
\hline Red-naped Sapsucker & 30 & $2-7$ & 8-12.4 & $233.3-700.0$ & $66.7-683.3$ & $32.7-88.2$ \\
\hline Hairy Woodpecker & 57 & $2-8$ & $8.6-15.0$ & $200.0-733.3$ & $50.0-783.3$ & $28.9-82.4$ \\
\hline Lewis' Woodpecker & 27 & $1-33$ & $2.9-10.1$ & $216.7-5,483.3$ & $50.0-350.0$ & $69.6-99.1$ \\
\hline Northern Flicker & 153 & $1-7$ & $4.6-12$ & $100.0-1,033.3$ & $31.25-416.7$ & $31.8-96.9$ \\
\hline Pileated Woodpecker & 121 & $1-3$ & $3.3-7.5$ & $133.3-650.0$ & $31.3-250.0$ & $40.9-92.9$ \\
\hline
\end{tabular}

- Total number of cycles.

ated differences in muscle function and acceleration performance. The scaling of muscle composition in passerines merits further investigation.

Recent studies indicate that the maximum mass-specific power available from the flight muscles in birds (and other flying animals) increases with body mass (Marden 1987, 1994, Ellington 1991). For birds, the scaling of pectoralis composition may explain this pattern. In the fixed-gear hypothesis (Goldspink 1977, Rayner $1977,1985 a)$, the homogeneity of fibers in the flight muscles of small birds supposedly results from space limitations on pectoralis mass. A different interpretation is that small birds are not constrained by their size and they never need the extra power available from $I$ (or $W$ ) fibers during even the most demanding flight modes (e.g. takeoff and steep ascent; Dial and Biewener 1993). Thus, having large numbers of such fiber types in their pectoralis is not selectively advantageous. The positive scaling of the percentage and cross-sectional diameter of $I$ fibers in the pectoralis in woodpeckers (Tables 1 and 2; Figs. 5 and 6A, B), therefore, may be in direct response to the positive scaling of the power required for flight (Pennycuick 1968b, Ellington 1991). The presence of $W$ fibers in larger species, such as the Rock Dove (Fig. 3C, D), could reflect further augmentation of the maximum available mass-specific power at even greater body masses than those exhibited in woodpeckers.

Although the scaling of fiber types (Fig. 6A, B) may offset the negative scaling for the massspecific power available from the pectoralis and, thereby, extend the upper limit for the ability to flap-bound, the power available for flapbounding nonetheless appeared to decrease with increasing body mass as predicted by the adverse-scaling hypothesis (Lighthill 1977, Rayner 1977, 1985a, DeJong 1983, Tobalske and Dial 1996). The wing kinematics (Fig. 8) and scaling relationships describing intermittent flight behavior in the field (Fig. 9) reflected a reduction in available power with increasing body mass because the percent cycle time spent flapping scaled positively, and the duration of bounding phase scaled negatively. However, the Pileated Woodpecker flapped on average for only $71.4 \%$ of the time within a flapping/nonflapping cycle (Table 5), indicating the potential for woodpeckers of greater body mass, beyond the range examined, to have sufficient power to use flapbounding flight.

Phylogenetic effects on muscle composition.-As

TABLE 7. Airspeeds during level flight.

\begin{tabular}{lll}
\hline \hline & \multicolumn{2}{c}{ Airspeed (m/s) } \\
\cline { 2 - 3 } \multicolumn{1}{c}{ Species } & \multicolumn{1}{c}{$\bar{x} \pm$ SD } & Range \\
\hline Downy Woodpecker & $8.5 \pm 0.5\left(2^{\mathrm{a}}\right)$ & $6.5-10.9\left(10^{\mathrm{b}}\right)$ \\
Red-naped Sapsucker & $9.3(1)$ & $6.1-11.6(13)$ \\
Hairy Woodpecker & $9.7(1)$ & $7.6-12.7(20)$ \\
Lewis' Woodpecker & $7.3 \pm 0.2(3)$ & $4.7-11.0(12)$ \\
Northern Flicker & $9.5 \pm 0.8(3)$ & $7.1-11.6(20)$ \\
Pileated Woodpecker & $9.9(1)$ & $7.5-11.6(11)$ \\
\hline
\end{tabular}

- Number of nests or independent geographic locations.

- Total number of flights. 

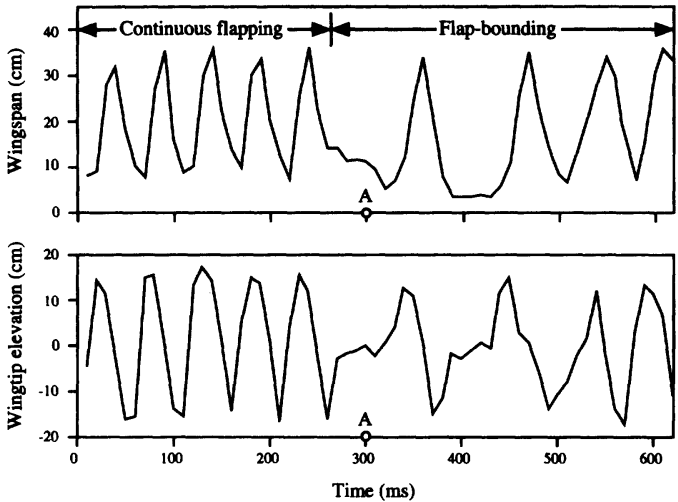

Fig. 11. Example of wing kinematics during flycatching flight in Red-naped Sapsucker, viewed directly behind bird, including intermittent bounds but not glides. Sequence shown was preceeded by takeoff and several wingbeats; after sequence, bird continued flying using flap-bounding flight. During wingbeats, wingspan was greatest at mid-downstroke and least at mid-upstroke, and wingtip elevation reached positive peak during the upstroke/downstroke transition and negative peak at the downstroke/upstroke transition. During first bound, wings were only partially flexed. Open circles marked A on time axes at $300 \mathrm{~ms}$ correspond to when bird ingested insect.

an alternative to a functional explanation, which implies that muscle composition is a phenotypic trait adapted in response to the selective pressure of adverse scaling of available power for flight, phylogenetic effects may explain patterns of variation in muscle composition. A phylogenetic effect is evident when species share certain phenotypic traits inherited from a common ancestor and, within lineages, closely-related species are more similar for the trait than are more distantly-related species (Miles and Dunham 1992, Losos and Miles 1994). Phylogenetic effects may result from selective or nonselective forces. Stabilizing selection could limit variation in a trait (Losos and Miles 1994). An example of a causal historical factor resisting phenotypic change regardless of selective pressure could be a shared developmental process (Lauder and Liem 1989, Losos and Miles 1994).

From studies of a broad array of avian taxa (George and Berger 1966, Rosser and George 1986a), it is apparent that species closely related phylogenetically tend to have similar fiber types in their muscles. For example, several passeriform species, including the European Starling, have both $I$ and $R$ fibers throughout their pectoralis muscles, but nevertheless have body masses less than $100 \mathrm{~g}$ (Rosser and George 1986a, Dunning 1993; Fig. 3). Thus, they share traits that are different from woodpeckers (Table 1; Figs. 3-5).

A phylogenetic effect could explain muscle composition in woodpecker species, but because hypothesized sister taxa in the Picidae shared similarites in both body mass and muscle composition, explanations based on scaling (i.e. functional, adaptive explanation) and phylogenetic effects are not mutually exclusive. Recent allozyme and mitochondrial-DNA studies (Tennant 1991, Moore 1995) suggest that the Downy and Hairy woodpeckers are sister taxa in the Campetherini, the Northern Flicker and Pileated Woodpecker are sister taxa in the Colaptini, and the Red-naped Sapsucker and Lewis' Woodpecker are sister taxa in the Melanerpini. Consistent with these proposed tribal affiliations, the pectoralis muscles in the Downy and Hairy woodpeckers stained similarly for SDH and GPD (Table 1; Fig. 5A, B, E, F), even to the extent that both species exhibited distinct variation in staining intensity among $R$ fibers (Fig. 4C, D). Likewise, the Northern Flicker and Pileated Woodpecker muscles stained similarly for GPD, but distinctly different from GPD staining observed in the other woodpecker species (Fig. 5). Muscle composition differed between the Red-naped Sapsucker and the Lewis' Woodpecker (Tables 1 and 2; Figs. 5 and 6). However, using genetic distance as a measure of the closeness of their phylogenetic relationship, these species apparently diverged from a common ancestor considerably earlier than the divergence between the Downy and Hairy woodpeckers, or the Pileated Woodpecker and Northern Flicker (Tennant 1991, Moore 1995 pers. comm.).

Alternative hypotheses regarding phylogenetic relationships within the Picidae certainly exist (Burt 1930, Goodge 1972, Swierczewski and Raikow 1981, Short 1982, Lanyon and Zink 1987, Tennant 1991, Moore 1995). Some of these hypotheses differ in details that could alter interpretation of phylogenetic effects in my study, but Tennant (1991) carefully reviewed all previously-existing alternatives when proposing the phylogeny outlined above.

Relationships between wing design and flight behavior.-The geometric similarity of wing dimensions observed in woodpeckers was consistent with linear trends evident in broad surveys of flying animals (Greenewalt 1962, Ray- 
ner 1988, Norberg 1990; Tables 3 and 4; Fig. 7). The slope describing the scaling of log wing area was slightly greater than would be predicted (Fig. 7A), but similar, minor deviations also are observed within other closely-related groups of birds (Norberg 1990). Log aspect-ratio and log wing-shape indices showed slight negative scaling, whereas geometric similarity should result in independence with body mass (Fig. 7E, F). It is unlikely that these departures are important functionally. For both variables, the correlation coefficients were not statistically significant, due at least in part to the relatively high aspect-ratio index of the wings in the Rednaped Sapsucker and the high wing-shape index (wing pointedness) in this species and in the Lewis' Woodpecker (Tables 3 and 4; Fig. 7E, F). Given that the slope of RMA regression was obtained by dividing the slope of a least-squares regression by the absolute value of the correlation coefficient (Sokal and Rohlf 1981), any scatter in the data had the effect of inflating the slope.

The scaling relationships describing wing kinematics and flight speeds among woodpeckers were similar to what would be expected for birds with geometrically similar wings (Tables 5-7; Figs. 8-10). With the Lewis' Woodpecker excluded from the sample, log flight speed scaled as $M^{0.07}$, slightly less than the predicted value of $M^{0.17}$ for the scaling of any characteristic flight speed (e.g. $V_{\mathrm{mp}}$ or $V_{\mathrm{mr}} ;$ Norberg 1990). Similarly, log wingbeat frequency scaled as $M^{-0.40}$, which was close to the predicted value of $M^{-0.33}$ (Greenewalt 1962, Norberg 1990). With specific regard to intermittent flight, Rayner (1977, 1985a) predicted that the percentage of time spent flapping within a cycle should scale proportional to $M^{0.17}$, and among woodpeckers, the $\log$ of this variable scaled as $M^{0.15}$.

Aside from the moderately greater wing-shape index in the Lewis' Woodpecker, this species did not show marked departures from RMA regression lines describing the scaling of linear wing dimensions or surface area with body mass (Fig. 7A, B, D-F). This is somewhat surprising because previous studies of the wing in the Lewis' Woodpecker (Burt 1930, Baldwin and Schneider 1963, Bock 1970) suggested that, for its body mass, this species has somewhat longer wing bones, longer primaries, and wings of much greater surface area in comparison to other woodpeckers (additional data in Degan and Popouici 1973). Burt (1930) used the length of the tibiotarsus to account for the effect of body mass, and this may not be directly comparable to body mass in my study. Bock (1970) reported data on wing dimensions from different sources, primarily Greenewalt (1962) and Baldwin and Schneider (1963), which were likely obtained using different measurement techniques. The surface area of a bird's wing changes dramatically as a function of the extent to which the wing is spread (Pennycuick 1989), which is why I attempted to standardize my measurements for comparison among species. For some measurements (e.g. wing area, wingspan, 8th primary length, and ulna length; Table 3; Fig. 7A, B, D), the Lewis' Woodpecker exhibited greater values than the Northern Flicker. This was contradictory to the overall positive scaling relationships for these variables, and consistent with the measurements of Baldwin and Schneider (1963).

Morphological correlates of prolonged gliding in the Lewis' Woodpecker have long been understood as being unusually low wing loading (body mass per unit wing area) and either increased wing pointedness (Baldwin and Schneider 1963) or increased wing breadth (Bent 1939, Bock 1970). However, my data revealed that neither wing shape nor wing area adequately accounted for gliding behavior in this species. Except for a high wing-shape index, wing morphometrics were not unusual in the Lewis' Woodpecker compared to the other woodpecker species, and the wing-shape index of the Red-naped Sapsucker was higher than that of the Lewis' Woodpecker (Table 3; Fig. 7A, B, D-F). The Red-naped Sapsucker never exhibited prolonged glides like the Lewis' Woodpecker (Figs. 8, 10, and 11), although the Rednaped Sapsucker, like all the woodpecker species, exhibited glide-bounding when landing (Fig. 2A).

Species in the Melanerpini, including the Rednaped Sapsucker and Lewis' Woodpecker, tend to have higher wing-shape indices than other woodpeckers (Tobalske 1994; Table 3; Fig. 7F). Phylogenetic effects (Miles and Dunham 1992, Losos and Miles 1994, see above) may explain their shared wing design, and this would represent an interesting case in which relatively closely-related species share characteristics of wing design but not pectoralis composition ( $\mathrm{Ta}$ ble 1; Fig. 5C, D, G, H). Wing pointedness also may be associated with migratory or flycatching behavior in the Melanerpini, as these behaviors 
are commonly exhibited by sapsucker species and the Lewis' Woodpecker (Bent 1939, Howell 1953, Baldwin and Schneider 1963, Lawrence 1966, Bock 1970, Raphael and White 1984; Figs. 10 and 11). I observed flycatching only in the Lewis' Woodpecker and Red-naped Sapsucker during this study, but the time spent at different species' nests was too brief to provide a rigorous quantitative measure of the frequency of flycatching behavior, as Bock (1970) provided for the Lewis' Woodpecker (also see Raphael and White 1984). However, given the potential for a relationship between foraging ecology, migration, and wing design, this is worthy of further investigation.

Effects of speed on intermittent flight.-Profile drag on the wings, which must be negligible during bounds because the wings are flexed, rises exponentially with increasing flight speed (Pennycuick 1968b, 1989, Rayner 1985a, 1988, 1991) and also should be proportional to wingbeat frequency. The reduction in profile drag during bounds is the primary reason that flapbounding is expected to offer a savings in power output relative to continuous flapping at fast flight speeds (Lighthill 1977, Rayner 1977, 1985a, Alexander 1982, DeJong 1983, Ward-Smith 1984a). Thus, during the relatively slow, level flights with relatively low wingbeat frequency in the Lewis' Woodpecker, it is likely that intermittent bounds did not offer a savings in profile drag relative to the costs incurred by flapping continuously. Gliding during foraging flights in the Lewis' Woodpecker may have been associated with even slower flight speeds than those exhibited during level flight. As a rough comparison to the level-flight speed in the Lewis' Woodpecker, which averaged $7.3 \mathrm{~m} / \mathrm{s}$ (Table 7), the continuous flapping and glide-bounding portions of four different foraging flights in one bird averaged $6.0 \mathrm{~m} / \mathrm{s}$. However, three-dimensional reconstructions of flight paths (e.g. Rayner and Aldridge 1985, Aldridge 1987) would be required for a more reliable measure of flight speed amid this species' frequent maneuvers and changes in altitude (Figs. 2B and 10).

Wind-tunnel studies have shown that several bird species are capable of using both flap-gliding and flap-bounding flight (Tobalske and Dial 1994, 1996, Tobalske 1995), and my observations revealed that Lewis' Woodpeckers have the ability to use both flight styles in the field. Moreover, as in the windtunnel studies, flapgliding was associated with slower-speed flight than flap-bounding. These data should help revise the perception that intermittent flight styles are fixed for bird species, because most mathematical models describing intermittent flight, with the exception of DeJong (1983), imply that a given species can use either flap-gliding or flap-bounding, but not both (Lighthill 1977, Rayner 1977, 1985a, Alexander 1982, WardSmith 1984a, b). Furthermore, glide phases in DeJong's (1983) model are very brief by comparison to bound phases. A facultative shift from flap-gliding to flap-bounding as speed increases probably represents an attempt to minimize mechanical and metabolic energy expenditure (per unit time) at all flight speeds (Tobalske and Dial 1994, 1996, Tobalske 1995).

Future studies. - Given the effects of body mass on muscle composition and intermittent flight in woodpeckers, an exciting area for further investigation would be to explore the scaling of these variables within other groups of closely-related species that exhibit intermittent flight. Species that frequently are observed flap-gliding may exhibit similar scaling relationships for the percent time flapping in a cycle but simply fly at slower flight speeds for a given body mass in comparison to species that tend to flap-bound. Relationships between wing design and intermittent flight style may become more apparent by studying at a broader phylogenetic scale. It would be worthwhile to test whether the pattern of increasing heterogeneity of fiber types in the pectoralis (Tables 1 and 2; Figs. 5 and 6) scales positively with body mass in other taxa. Future research on intermittent flight also should continue to quantify the extent of variation occurring within individuals. As in other species (Danielson 1988), the ranges were considerable for intermittent flight variables exhibited by woodpeckers (Tables 6 and 7). Explanations for this variation within individuals remains largely unexplored in the theoretical literature pertaining to intermittent flight (Lighthill 1977, Rayner 1977, 1985a, Alexander 1982, DeJong 1983, Ward-Smith 1984a, b), but such variation may be an important key to understanding the evolution of the behavior (e.g. Shaffer and Lauder 1985).

\section{ACKNOWLEDGMENTS}

I sincerely thank Claudine Tobalske for assistance in the field and encouragement during all aspects of this study. To many other people, I also extend my 
appreciation. Ken Dial provided scientific guidance and financial support. Doug Warrick, Andrew Biewener, Richard Hutto, Dona Boggs, Charles Leonard, and Erick Greene provided helpful comments while I developed the project and on the manuscript. Ulla Norberg, Ảke Norberg, Abbot Gaunt, and Gary Schnell also provided constructive criticism of the manuscript. John Hermanson and his research staff introduced me to histological staining techniques, and further assistance was provided by Dona Boggs and Isaure DeBuron-Connors. Robert Lee, Penny Reynolds, and Ted Garland assisted with statistical analysis of independent contrasts, and William Moore assisted with interpreting hypotheses of woodpecker phylogeny. Del Kilgore, Bill Granath, and Kerry Foresman provided invaluable research equipment and work space. Debbie Conway, Jeff Marks, Andy Perleberg, Chris Hill, Dona Boggs, Ken Dial, and Phil Wright assisted in collecting specimens. Generous loans of specimens or access to collections were provided by the following: Carnegie Museum of Natural History Section of Birds (Kenneth Parkes, Bradley Livezey, Jay Loughlin, and Scott Wood), Burke Museum at the University of Washington (Sievert Rohwer and Chris Wood), Connor Museum at Washington State University (Richard Johnston and Kevin Pullen), Museum of Natural Science at Louisiana State University (Donna Dittman, Diana Reynolds, and Fred Sheldon), and Museum of Comparative Zoology at Harvard University (Raymond Paynter). Patrick Gonzales of the U.S. Fish and Wildlife Service granted access to field areas at Metcalf National Wildlife Refuge. I note, with much appreciation, the birds I collected in conjunction with appropriate permits issued by the U.S. Fish and Wildlife Service (PRT 771277) and Montana Department of Fish, Wildlife, and Parks (1333). My work was supported by a Grant-in-Aid of Research (9206) I received from Sigma-Xi and a National Science Foundation Grant (IBN 92-11393) to Ken Dial.

\section{LITERATURE CITED}

ALDRIDGE, H. D. J. N. 1987. Turning flight of bats. J. Exp. Biol. 128:419-425.

AleXANDER, R. MCN. 1982. Optima for animals. Arnold, London.

BALDWIN, P. H., AND R. W. SCHNEIDER. 1963. Fligh 1 in relation to form of wing in the Lewis' Woodpecker. J. Colo.-Wyo. Acad. Sci. 5:58-59.

BENT, A. C. 1939. Life histories of North American woodpeckers. U.S. Natl. Mus. Bull. 174:1-334.

Baumel, J. J., A. S. King, A. M. LuCAS, J. E. Breazile, AND H. E. Evans. 1979. Nomina anatomica avium. Academic Press, London.

Bock, C. E. 1970. The ecology and behavior of the Lewis' Woodpecker (Asyndesmus lewis). Univ. Calif. Publ. Zool. 92:1-100.

BuRNIE, D. 1988. Bird. Eyewitness Books. Alfred A. Knopf, New York.
BURT, W. H. 1930. Adaptive modifications in the woodpeckers. Univ. Calif. Publ. Zool. 32:455-524.

COMPUTER ASSOCIATES INTERNATIONAL, INC. 1992. Cricket Graph III user guide. Computer Associates International, Inc., Islandia, New York.

DANIELSON, R. 1988. Parametre for fritflyvende småfugles flugt. Dan. Ornithol. Foren. Tidsskr. 82: 1-2.

DegaN, C., AND N. PopovicI. 1973. Variaţii biometrice ale scheletului şi ale musculaturii aripilor la citeva specii de păsări din familia picidelor. Studia Universitatis Babeş-Bolyai 18:91-98.

DeJong, M. J. 1983. Bounding flight in birds. Ph.D. dissertation, Univ. Wisconsin, Madison.

DiAL, K. P., AND A. A. BIEWENER. 1993. Pectoralis muscle force and power output during different modes of flight in pigeons (Columba livia). J. Exp. Biol. 176:31-54.

Dial, K. P., S. R. KaPlan, G. E. Goslow, JR., AND F. A. JENKINS, JR. 1988. A functional analysis of the primary upstroke and downstroke muscles in the domestic pigeon (Columba livia) during flight. J. Exp. Biol. 134:1-16.

DUNNING, J. B., JR. (Ed.). 1993. CRC handbook of avian body masses. CRC Press, Boca Raton, Florida.

Ellington, C. P. 1991. Limitations on animal flight performance. J. Exp. Biol. 160:71-91.

FELSENSTEIN, J. 1985. Phylogenies and the comparative method. Am. Nat. 125:1-15.

Garland, T., JR., P. H. HARVeY, AND A. R. IVES. 1992. Procedures for the analysis of comparative data using phylogenetically independent contrasts. Syst. Biol. 41:18-32.

GeORGE, J. C., AND A. J. Berger. 1966. Avian myology. Academic Press, London.

GoldSPINK, G. 1977. Mechanics and energetics of muscle in animals of different sizes, with particular reference to the muscle fibre composition of vertebrate muscle. Pages 27-55 in Scale effects in animal locomotion (T. J. Pedley, Ed.). Academic Press, New York.

GolDSPINK, G. 1981. The use of muscles during flying, swimming, and running from the point of view of energy saving. Symp. Zool. Soc. Lond. 48:219-238.

GoODGE, W. R. 1972. Anatomical evidence for phylogenetic relationships among woodpeckers. Auk 89:65-85.

GreENEWALT, C. H. 1962. Dimensional relationships for flying animals. Smithson. Misc. Coll. 144:146.

GuTH, L., AND F. J. SAMAHA. 1970. Procedure for the histochemical demonstration of actomyosin ATPase. Exp. Neurol. 38:365-367.

HeRmanson, J. W., AND R. C. Foehring. 1988. Histochemistry of flight muscles in the Jamaican fruit bat, Artibeus jamaicensis: Implications for motor control. J. Morphol. 196:353-362. 
HOWELl, T. R. 1953. Racial and sexual differences in migration in Sphyrapicus varius. Auk 70:118-126.

Hudson, D. M., AND M. H. BERNSTEIN. 1983. Gas exchange and energy cost of flight in the Whitenecked Raven, Corvus cryptoleucus. J. Exp. Biol. 13: 121-130.

LANYON, S. M., AND R. M. ZINK. 1987. Genetic variation in piciform birds: Monophyly and generic and familial relationships. Auk 104:724-732.

LAUDER, G. V., AND K. F. LIEM. 1989. The role of historical factors in the evolution of complex organismal functions. Pages 63-78 in Complex organismal functions: Integration and evolution in vertebrates (D. B. Wake and G. Roth, Eds.). John Wiley and Sons, New York.

LAWRENCE, L. DE K. 1966. A comparative life-history study of four species of woodpeckers. Ornithol. Monogr. 5.

LightHILL, M. J. 1977. Introduction to the scaling of aerial locomotion. Pages 365-404 in Scale effects in animal locomotion (T. J. Pedley, Ed.). Academic Press, New York.

LOEB, G. E., AND C. GANS. 1986. Electromyography for experimentalists. Univ. Chicago Press, Chicago.

Losos, J. B., AND D. B. Miles. 1994. Adaptation, constraint, and the comparative method: Phylogenetic issues and methods. Pages 60-98 in Ecological morphology: Integrative organismal biology (P. C. Wainwright and S. M. Reilly, Eds.). Univ. Chicago Press, Chicago.

MARDEN, J. H. 1987. Maximum lift production during takeoff in flying animals. J. Exp. Biol. 130: 235-258.

MARDEN, J. H. 1994. From damselflies to pterosaurs: How burst and sustainable flight performance scale with size. Am. J. Physiol. 266:R1077-R1084.

MEYERS, R. A. 1993. Gliding flight in the American Kestrel (Falco sparverius): An electromyographic study. J. Morphol. 215:213-224.

Microsoft CoRPORATION. 1991. Microsoft Excel version 3.0 user's guide. Microsoft Corp., Redmond, Washington.

Miles, D. B., AND A. E. Dunham. 1992. Comparative analyses of phylogenetic effects in the life history patterns of iguanid reptiles. Am. Nat. 139:848869.

MOORE, W. S. 1995. Inferring phylogenies from mtDNA variation: Mitochondrial-gene trees versus nuclear-gene trees. Evolution 49:718-726.

NORBERG, U. M. 1990. Vertebrate flight: Mechanics, physiology, morphology, ecology, and evolution. Springer-Verlag, Berlin.

NORBERG, U. M., AND J. M. V. RAYNER. 1987. Ecological morphology and flight in bats (Mammalia, Chiroptera): Wing adaptations, flight performance, foraging strategies and echolocation. Phil. Trans. R. Soc. Lond. B 316:335-427.
NoRUSIS, M. J. 1990. SPSS base package user's guide. SPSS, Inc., Chicago.

Padykula, H. A., AND E. Herman. 1955. The specificity of the histochemical methods of adenosine triphoshatase. J. Histochem. Cytochem. 3:170-195.

PENNYCUICK, C. J. 1968a. A wind-tunnel study of gliding flight in the pigeon Columba livia. J. Exp. Biol. 49:509-526.

PENNYCUICK, C. J. 1968b. Power requirements for horizontal flight in the pigeon Columba livia. J. Exp. Biol. 49:527-555.

PENNYCUICK, C. J. 1989. Bird flight performance: A practical calculation manual. Oxford Univ. Press, Oxford.

PenNyCuick, C. J., AND M. A. Rezende. 1984. The specific power output of aerobic muscle, related to the power density of mitochondria. J. Exp. Biol. 108:377-392.

RAPHAEL, M. G., AND M. WhITE. 1984. Use of snags by cavity-nesting birds in the Sierra Nevada. Wildl. Monogr. 86:1-66.

RAYNER, J. M. V. 1977. The intermittent flight of birds. Pages 437-443 in Scale effects in animal locomotion (T. J. Pedley, Ed.). Academic Press, New York.

RAYNER, J. M. V. 1985a. Bounding and undulating flight in birds. J. Theor. Biol. 117:47-77.

RAYNER, J. M. V. 1985b. Linear relations in biomechanics: The statistics of scaling functions. J. Zool. (Lond.) A206:415-439.

RAYNER, J. M. V. 1988. Form and function in avian flight. Curr. Ornithol. 5:1-66.

RAYNER, J. M. V. 1991. Wake structure and force generation in avian flapping flight. Pages 702715 in Acta XX Congressus Internationalis Ornithologici (B. D. Bell, Ed.). Christchurch, New Zealand, 1990. New Zealand Ornithol. Congr. Trust Board, Wellington.

RAYNER, J. M. V., AND H. D. J. N. AldRIDGE. 1985. Three-dimensional reconstruction of animal flight paths and the turning flight of microchiropteran bats. J. Exp. Biol. 118:247-265.

Rosser, B. W. C., AND J. C. GeORGE. 1986a. The avian pectoralis: Histochemical characterization and distribution of muscle fiber types. Can. J. Zool. 64:1174-1185.

Rosser, B. W. C., AND J. C. GeORge. 1986b. Slow muscle fibers in the pectoralis of the Turkey Vulture (Cathartes aura): An adaptation for soaring flight. Zool. Anz. 217:252-258.

SCHMIDT-NiELSEN, K. 1984. Scaling: Why is animal size so important? Cambridge Univ. Press, Cambridge.

Scholey, K. D. 1983. Developments in vertebrate flight. Ph.D. dissertation, Univ. Bristol, United Kingdom.

ShafFer, H. B., AND G. V. LAUdER. 1985. Aquatic prey capture in ambystomatid salamanders: Patterns 
of variation in muscle activity. J. Morphol. 183: 273-284.

SHORT, L. L. 1982. Woodpeckers of the world. Delaware Museum of Natural History, Greeneville.

SKUTCH, A. F. 1985. Life of the woodpecker. Ibis Publishing. Co., Santa Monica, California.

SOKAL, R. R., AND F. J. Rohlf. 1981. Biometry, 2nd ed. W. H. Freeman and Co., New York.

SWEENEY, H. L., M. J. KUSHMERICK, K. MABUCHI, J. GERGELY, AND F. A. STRETER. 1986. Velocity of shortening and myosin isozymes in two types of rabbit fast-twitch muscle fibers. Am. J. Physiol. 2512:431-434.

SWIERCZEWSKI, E. V., AND R. J. RAIKOW. 1981. Hind limb morphology, phylogeny, and classification of the piciformes. Auk 98:466-480.

Tennant, M. 1991. Phylogenetic systematics of the picinae. Ph.D. dissertation, Wayne State Univ., Detroit, Michigan.

TOBALSKE, B. W. 1994. Effects of speed and body mass on the intermittent flight of birds. Ph.D. dissertation, Univ. Montana, Missoula.

TOBALSKE, B. W. 1995. Neuromuscular control and kinematics of intermittent flight in the European Starling (Sturnus vulgaris). J. Exp. Biol. 198:12591273.

TOBALSKE, B. W., AND K. P. DiAL. 1994. Neuromuscular control and kinematics of intermittent flight in Budgerigars (Melopsittacus undulatus). J. Exp. Biol. 187:1-18.

TOBALSKE, B. W., AND K. P. Dial. 1996. Flight kinematics of Black-billed Magpies and pigeons over a wide range of speeds. J. Exp. Biol. 199:263-280.

WARD-SMITH, A. J. 1984a. Analysis of the aerodynamic performance of birds during bounding flight. Math. Biosci. 68:137-147.

WARD-SmITH, A. J. 1984b. Aerodynamic and energetic considerations relating to undulating and bounding flight in birds. J. Theor. Biol. 48:215229.

WATTENBERG, L. W., AND J. L. LeONG. 1960. Effects of coenzyme $Q_{10}$ and menadione on succinate dehydrogenase activity as measured by tetrazolium salt reduction. J. Histochem. Cytochem. 8:296-303. 